71

\author{
المردود الإقتصادى لنظم الرى لأهم الحاصلات الزراعية فى الأراضى الجديدة بمحافظة

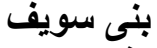 \\ أ.د.محمد أحمد سعيد د. ديد نعيمى فيصل م.عبدالرحمن أبوهشيمة عبدالرحمن \\ * قسم الإقتصاد الزراعى ـ كلية الزر اعة - جامعة الفيوم
}

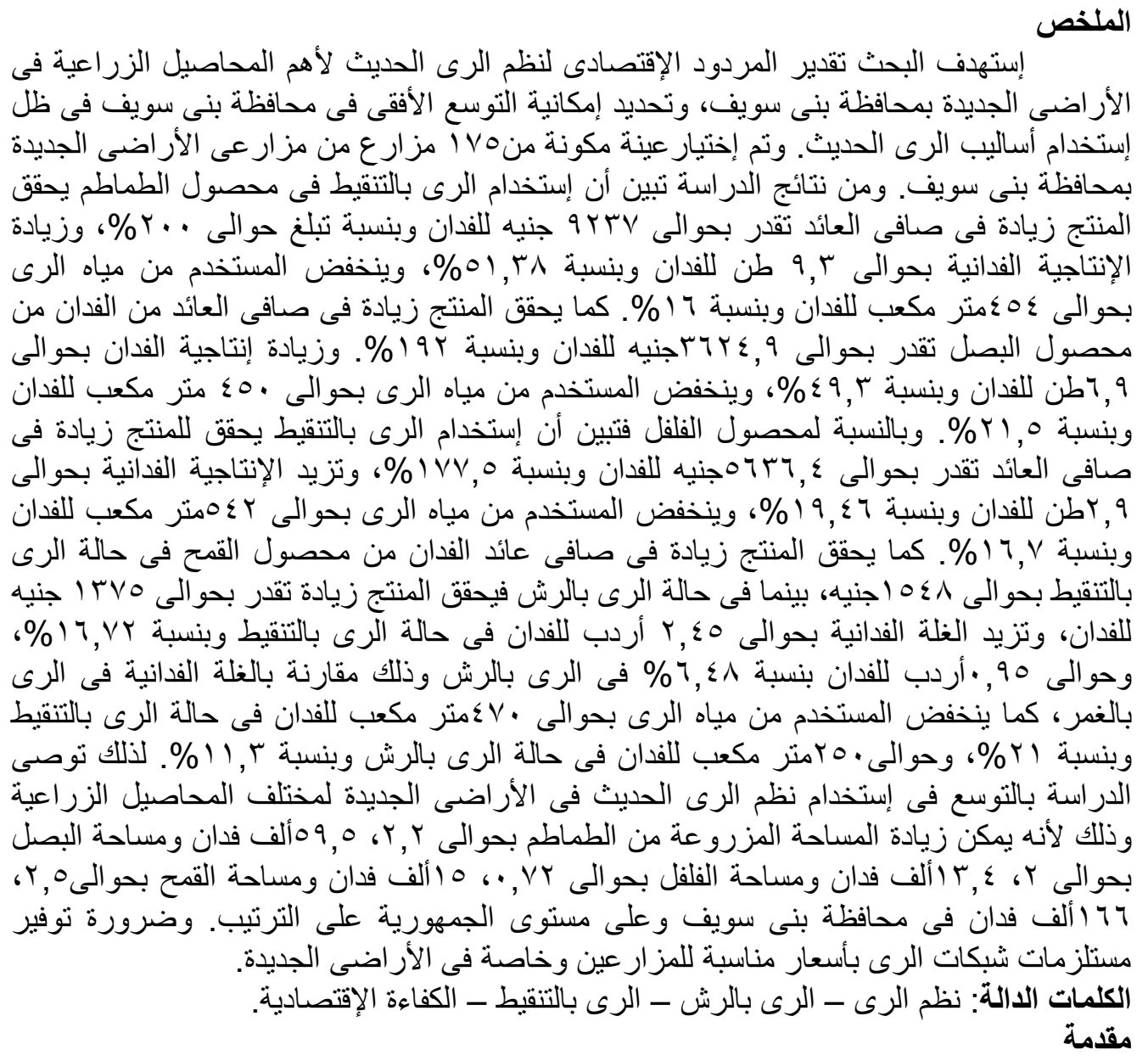

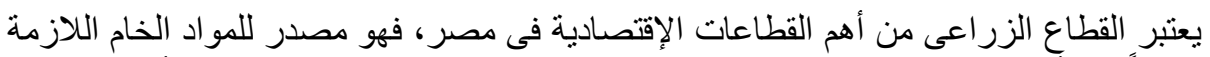

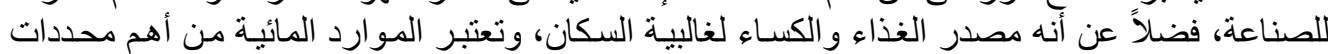

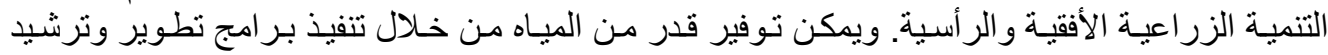

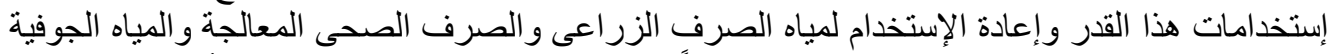

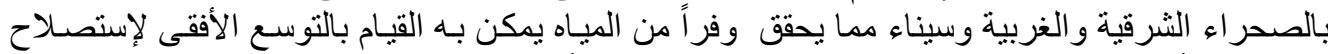

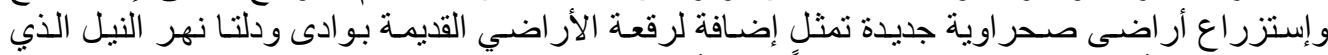

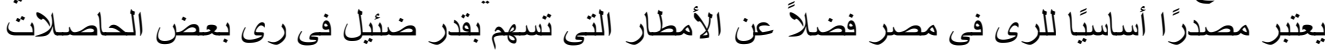
الثتوى كالقمح و الثعبير بالساحل الرى الثمالي.

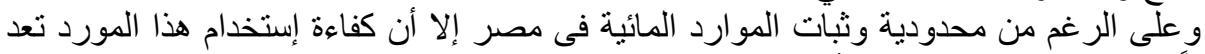

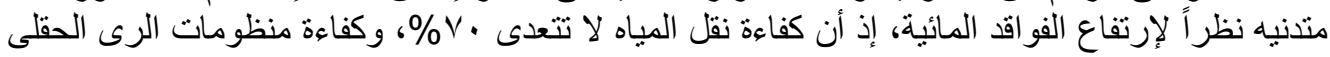

Fayoum J. Agric. Res. \& Dev., Vol. 30, No.2, July, 2016 
79

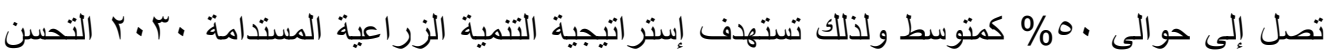

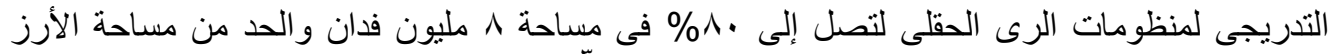

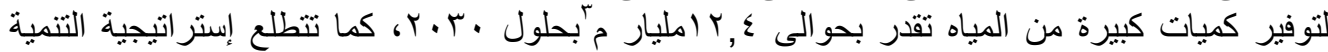

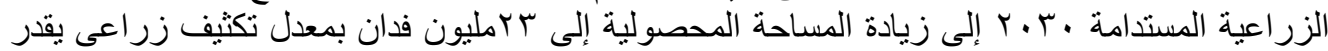

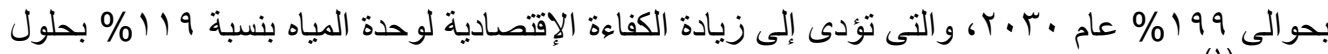

(') r.r.

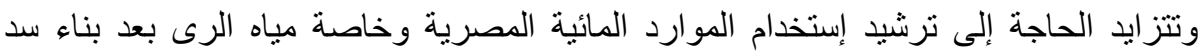

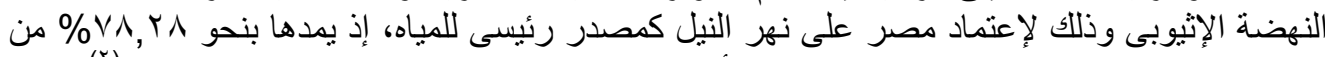

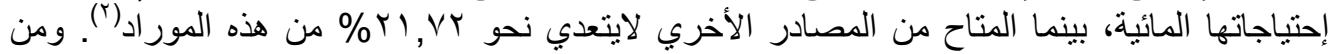

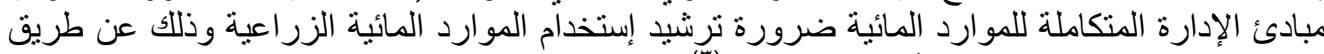

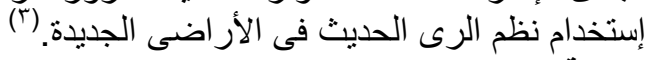
مشكلة البحث

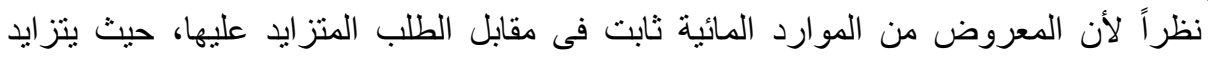

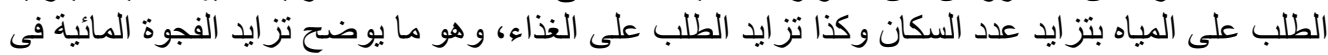

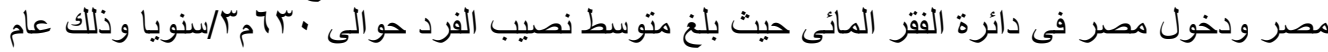

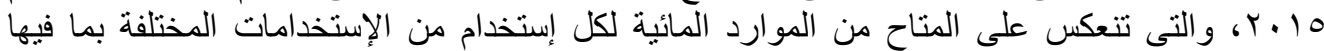

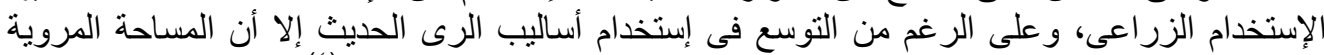

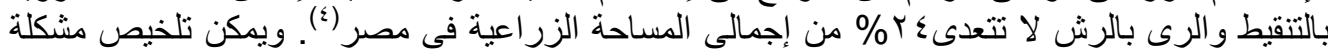

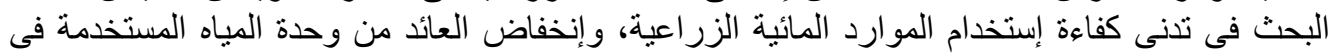

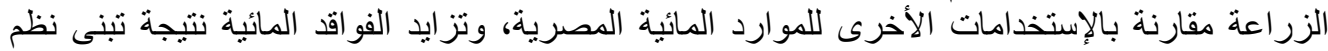

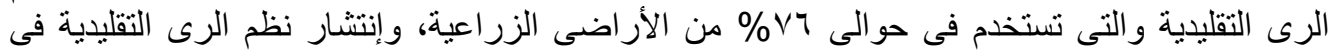

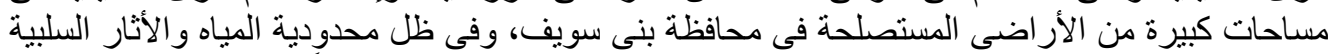

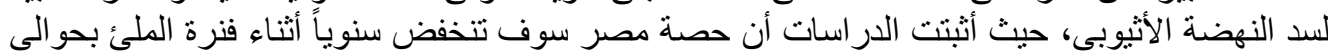

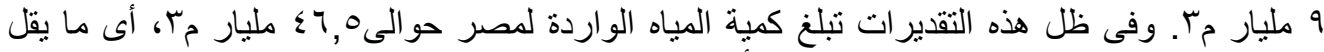

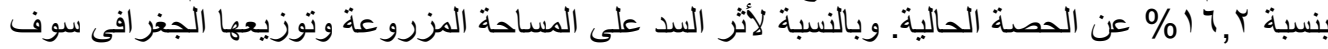

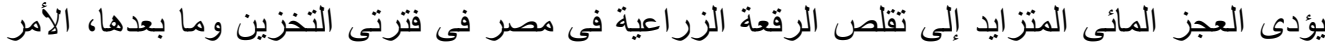

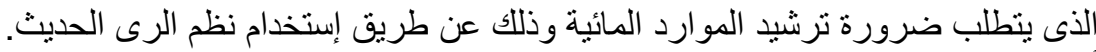

أهداف البحث

يهدف البحث إلى تقدير المردود الإقتصادى لنظم الرى الحديث لأهم المحاصيل الزراعية فى الزى

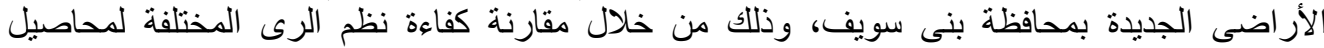

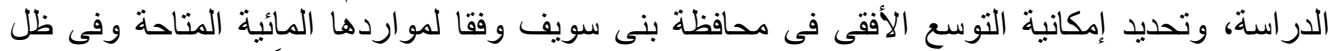
إستخدام أساليب الرى الحديث، وتقدير دوال الإنتاج و التكاليف لمحاصيل الدراسة وفقاً لنظم الرى الئلئ المختلفة.

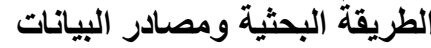

إعتمدت الدراسة على إستخدام أساليب التحليل الوصفى والكمى وذللك بهدف قياس كفاءة إستخدام

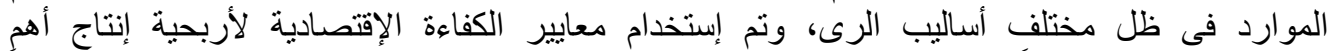

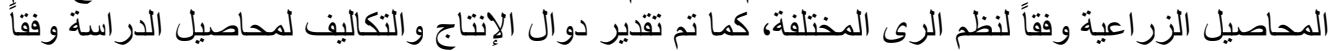

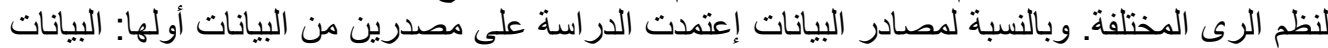

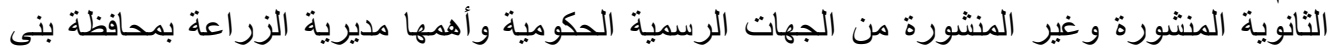

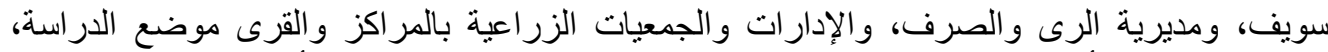

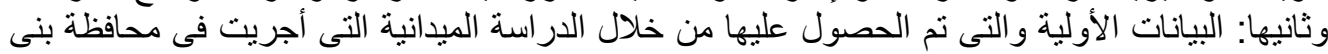

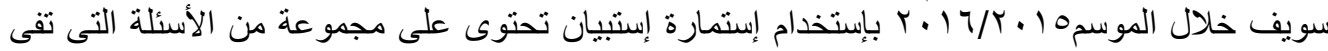

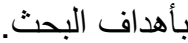

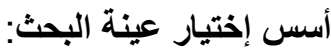

Fayoum J. Agric. Res. \& Dev., Vol. 30, No.2, July, 2016 
V.

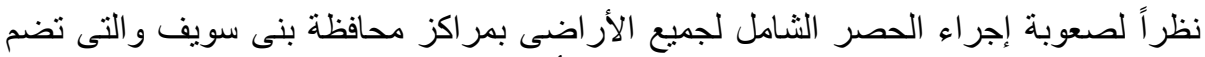

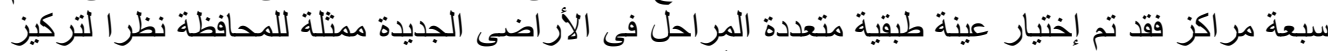

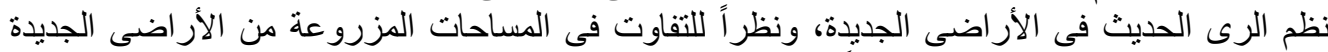

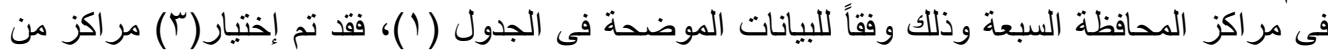

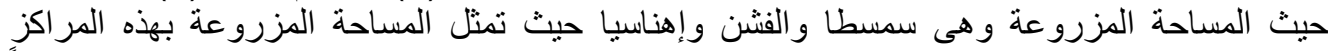

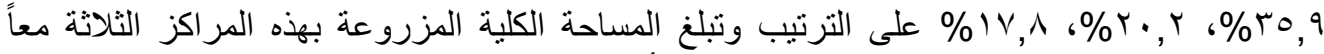

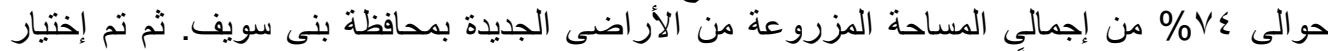

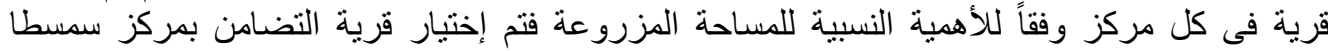

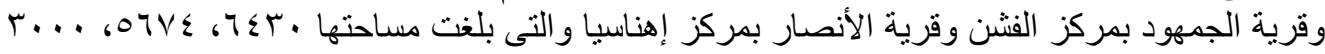

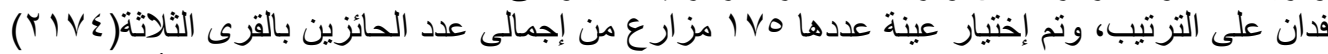

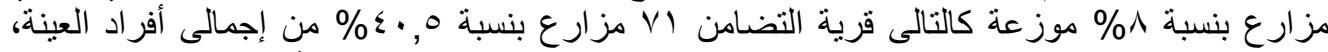

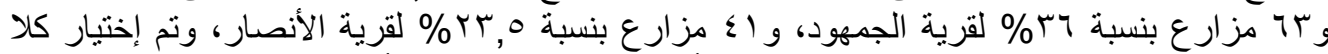

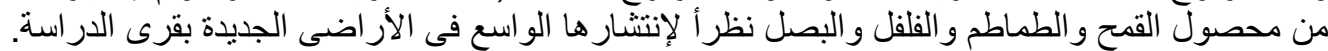

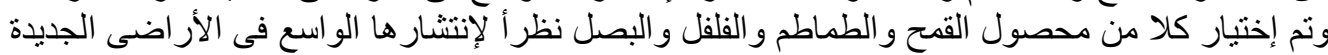

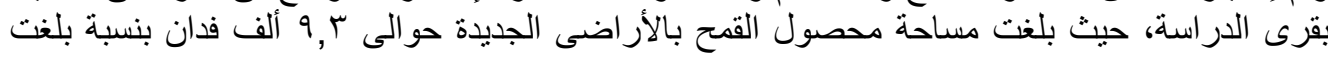

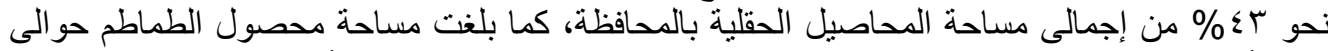

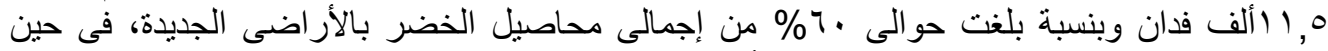

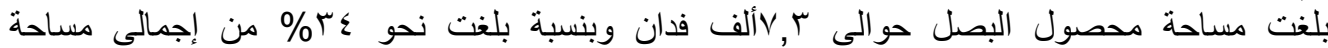

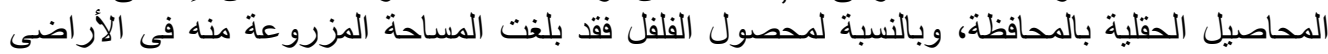

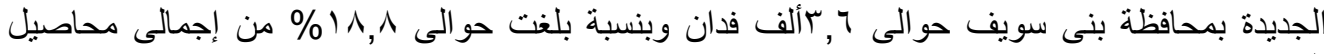

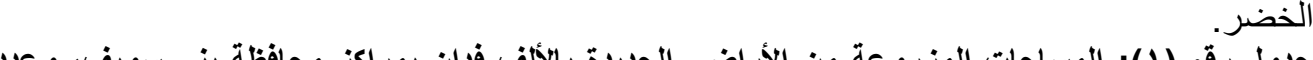

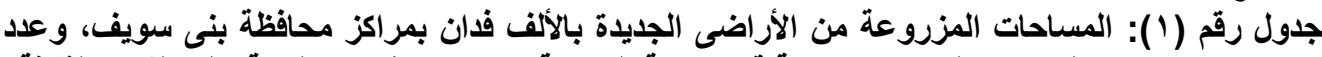

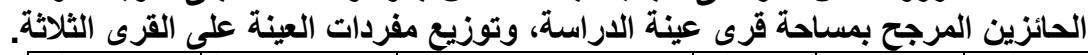

\begin{tabular}{|c|c|c|c|c|c|c|}
\hline حجم العينة & \% إجمالى العينة & الحائزين المرجح بالمساحة لعندة & القرية & $\%$ & الأرزرى المسة من & المركز \\
\hline VI & $\varepsilon \cdot, 0$ & YTIA,O & التضامن & $r 0,9$ & 14,97 & سمسطا \\
\hline 84 & 4 & $r \cdot \leqslant \neg, r$ & الجمهود & $r \cdot, r$ & $v, \wedge v$ & الفشن \\
\hline \&1 & $r r, O$ & $1+1,7$ & الأنصار & $I V, \Lambda$ & 7,94 & إهناسيا \\
\hline \multirow[t]{5}{*}{ IVo } & $1 \ldots$ & $\Delta V \cdot 7, \xi$ & الإجمالى & $\Lambda, V$ & $r, r q$ & بنى سويف \\
\hline & & & & $\wedge, \uparrow$ & $r, r o$ & الواسطى \\
\hline & & & & 0,7 & $r, 11$ & ن ناصر \\
\hline & & & & $r, r$ & $1, r T$ & ببا \\
\hline & & & & $1 \ldots$ & $r \wedge, q r$ & الإجمالى \\
\hline
\end{tabular}

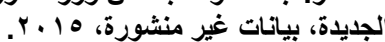

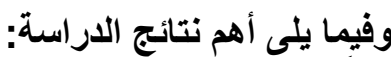

أولاً: مؤشرات الكفاعة الإقتصادية لنظم الرى لأهم المحاصيل الزراعية موضع الأراسة:

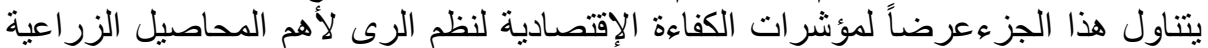

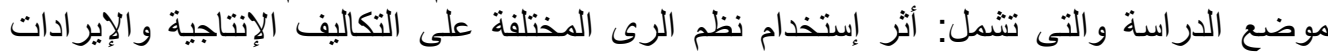

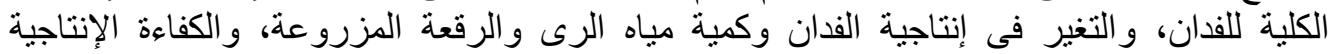
والإقتصادية لوحدة مياه الرى المعنى المستخدمة.

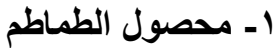

Fayoum J. Agric. Res. \& Dev., Vol. 30, No.2, July, 2016 
أـ أثر إستخدام نظم الرى المختلفة على بنود تكاليف إنتاج فدان الطماطم وإيراداته:

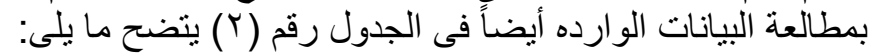

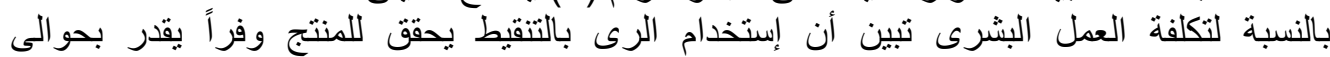

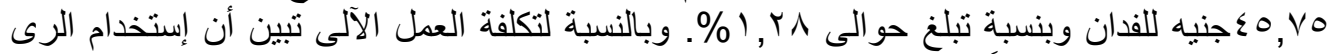

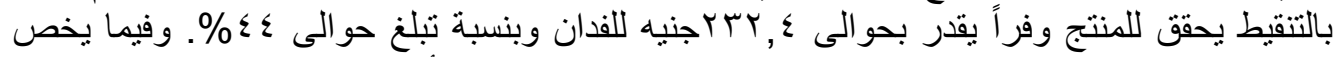

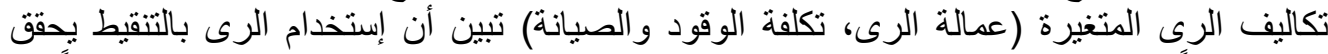

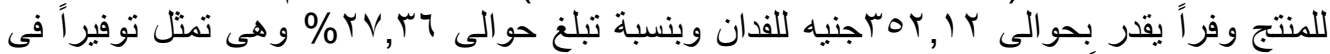

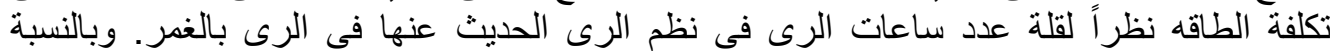

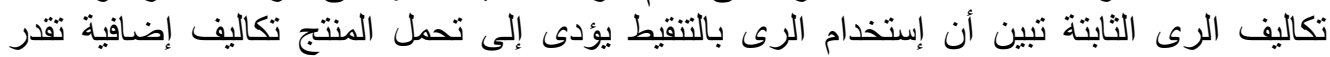

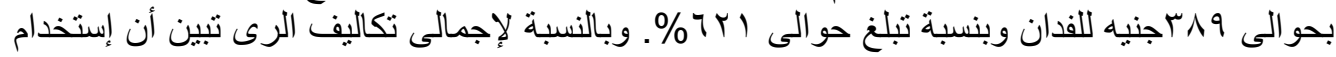

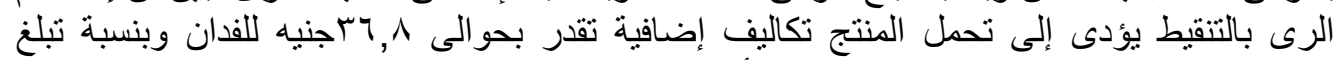

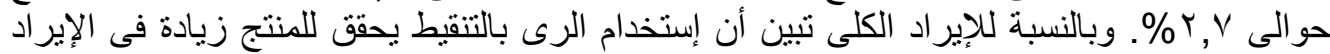

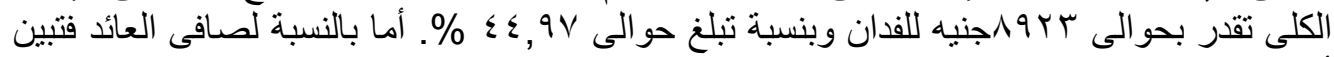

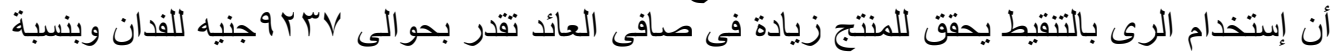

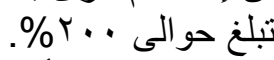
جدول رقم (r): أثر إستخدام نظم الرى على تكاليف وإيرادات القدان من محصول الطماطم والبصل

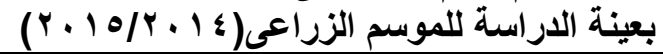

\begin{tabular}{|c|c|c|c|c|c|c|c|c|}
\hline \multicolumn{4}{|c|}{ البصل } & \multicolumn{4}{|c|}{ الطماطم } & المحصول \\
\hline$\%$ & مقدار التغير & الرى بالغمر & الرى بالتنقيط & $\%$ & مقدار التغير & الرى بالغمر & الرى بالتنقيط & البيان \\
\hline $0, \mathrm{~V}$ & $(1+4, V)$ & THAT, & $T Y \leq 7,7$ & $1, r \wedge$ & $\left(\leqslant 0, \vee_{0}\right)$ & roTh, vo & rort & العمل البشرى* \\
\hline$r V, V$ & $(1) \varepsilon, \cdot)$ & \&11 & KQV & $\varepsilon \leqslant$, & (YKY, rᄉ) & OTV,IN & $r 9 \leqslant, \Lambda$ & العمل الآلى* \\
\hline Yo,1 & $\left(Y^{\prime} q, \varepsilon\right)$ & 1174,9 & $\Lambda V \cdot, 0$ & $r V, r T$ & $(T \circ Y, 1 T)$ & 1Y人 , 9T & $9 r \varepsilon, 1$ & تكاليف الرى المتغيرة \\
\hline$V \leqslant r, 1$ & ra7, r & or, $\varepsilon$ & $\varepsilon \leqslant 9, V$ & $T Y 1, V$ & $r \wedge \wedge, q \leq$ & $7 r, 07$ & $\leqslant 01,0$ & تكاليف الرى الثابتة \\
\hline 1,0 & I.r. & IYI7,rr & ITY. & T,YY & $r 4,1$ & $1 \% \leqslant 9,0$ & $1 \% \wedge 7, r$ & إجمالي تكاليف الرى \\
\hline ro,r & $r \cdot r, 0$ & A.r,r & $1 \cdots 7, \wedge$ & $9,7 \varepsilon$ & $1 \leqslant \Lambda, r_{0}$ & $10 \mathrm{r}, \mathrm{VO}$ & $17 \lambda \vee, 1$ & السماد البلاى \\
\hline$\varepsilon \wedge, 1$ & $(\vee \cdot 9,0)$ & $1 \leqslant V \leqslant, V$ & $V 70, r$ & ov, 7 . & $(99 \vee, \vee)$ & $|V T|, 9$ & $V \Gamma \varepsilon, r$ & الأسمدة الأزوتية \\
\hline $9 \leqslant, r$ & $(0 \wedge), \vee)$ & $717, \mathrm{~V}$ & ro & $\lambda \varepsilon, 7 \varepsilon$ & $(\Sigma \pi Y, \wedge \wedge)$ & $0 \leq 7, \wedge \wedge$ & $\wedge \varepsilon$ & الأسمدة الفوسفاتية \\
\hline 190 & $(r q, \cdot)$ & $r$. & 09 & $T K \wedge, \wedge \varepsilon$ & $\varepsilon \cdot 1,0$ & $r 17, V$ & $V Y \xi, V O$ & الأسمدة البوتاسية \\
\hline- & VOV, Y & . & VOV,Y & - & $11 . r, r_{0}$ & . & $11 . r, r_{0}$ & العناصر الصغرى \\
\hline $1 \cdot, 7$ & $(1) \vee, \varepsilon)$ & 111. & 994,7 & $V, \leqslant V$ & $\left(11 \wedge, r_{0}\right)$ & $10 \wedge r, 1$ & $1 \leq 7 \leq, V_{0}$ & المبيدات \\
\hline 00,1 & $V Y \cdot, \varepsilon$ & $1 T \cdot V$ & $Y \cdot Y V, \varepsilon$ & 7,77 & $(100)$ & TMTO & rIV. & التقاوى \\
\hline 1,1 & 170,1 & $9 T \leqslant Y$ & $90 \cdot v, 1$ & T,YY & $(r, \varepsilon, 1)$ & $T r \leqslant \lambda V$ & ITIVY, & إجمالى التكاليف \\
\hline 1,0 & 170,1 & 11.94 & IIrOV, I & $r, \cdot T$ & $(\Gamma) \leq, 1)$ & lorrV & $1 \leq q r Y, 9$ & إجمالى التكاليف الكلية \\
\hline$r q, r$ & rVq. & 1rqA. & $17 V V$. & $\varepsilon \varepsilon, 9 V$ & N9Yr, 19 & $19 \lambda r \Lambda, r_{0}$ & YAVT,$\leqslant \varepsilon$ & الإيراد الكلى \\
\hline 194 & MTY $\varepsilon, 9$ & $1 \wedge \wedge \Lambda$ & 0014 & r.., Vo & qrTV,Yq & $\sum 7 \cdot 1, Y_{0}$ & ITATA,O & صافى العائد \\
\hline
\end{tabular}

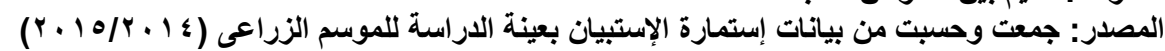

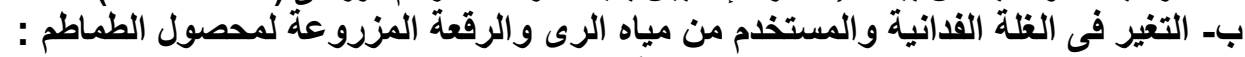

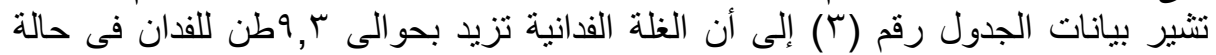

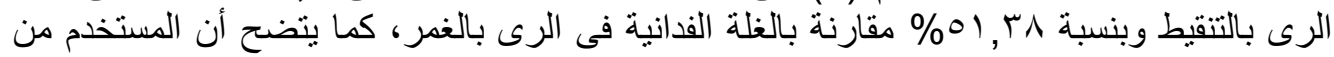

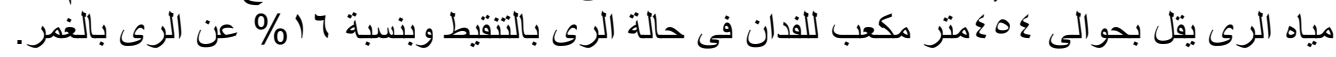

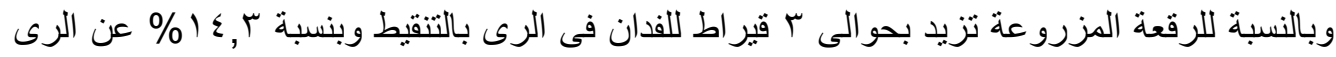

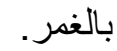

ج- الكفاعة الإنتاجية والإقتصادية لوحدة المياه المستخدمة فى رى الطماطم :

Fayoum J. Agric. Res. \& Dev., Vol. 30, No.2, July, 2016 
VY

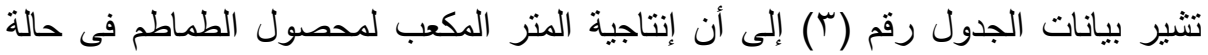

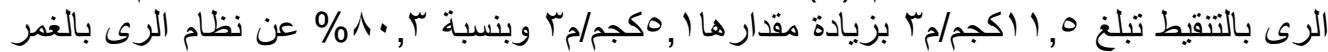

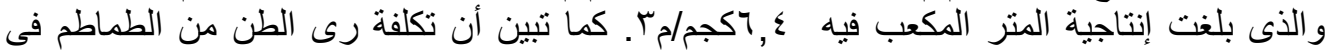

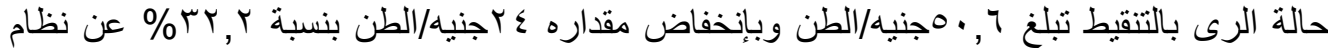

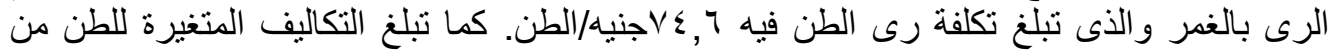

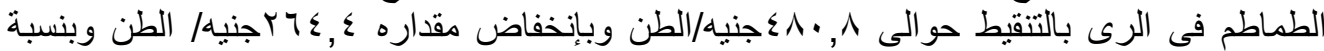

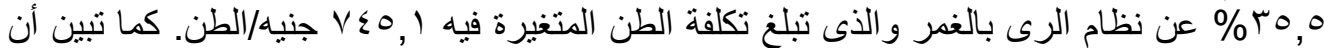

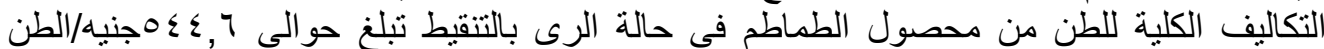

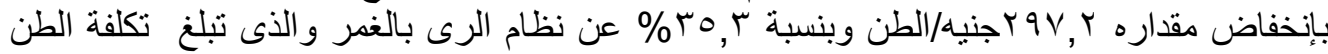

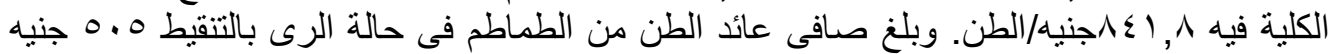

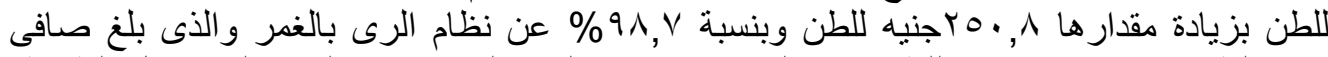

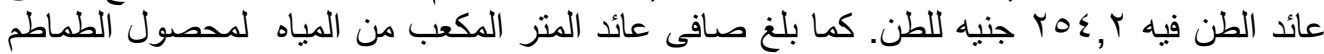

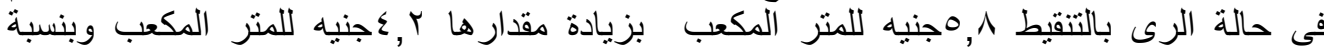
r roN, ,

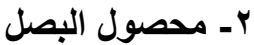

أـ أثر إستخدام نظم الرى المختلفة على بنود تكاليف إنتاج الفدان من البصل وإيراداته:

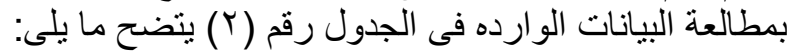

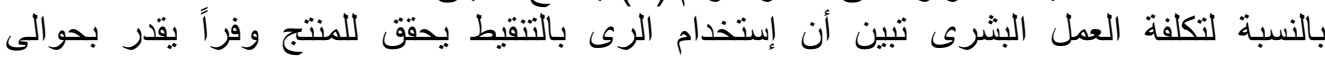

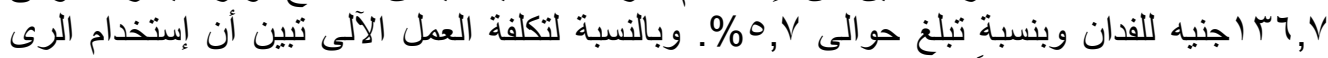

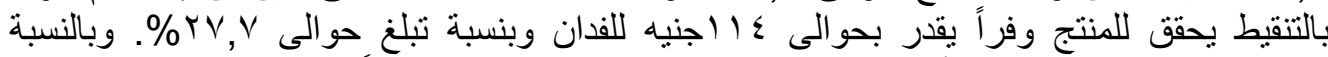

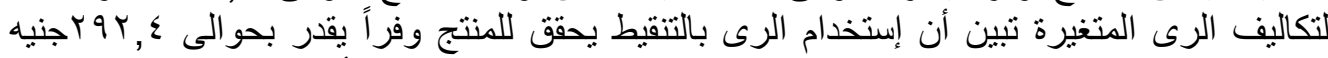

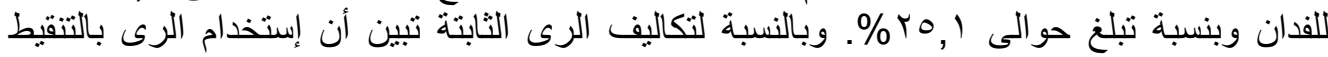

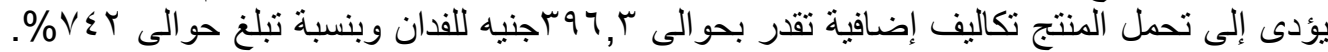

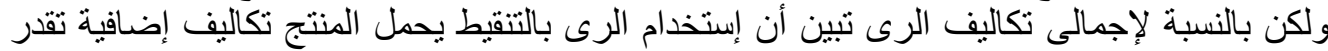

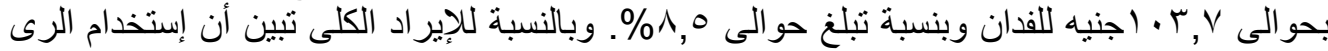

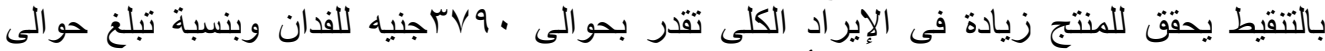

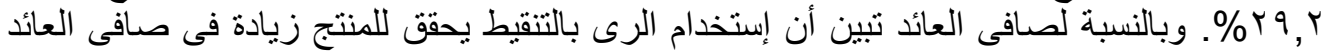

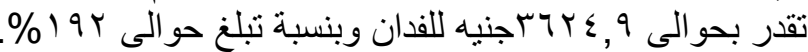

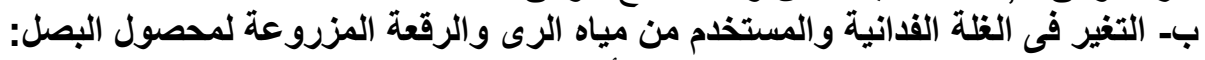

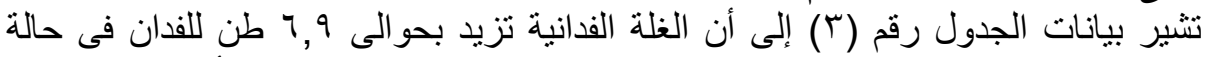

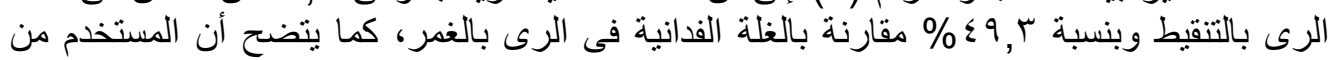

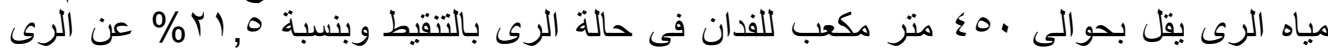

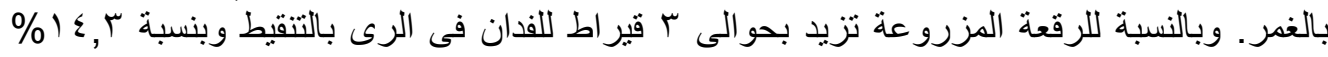

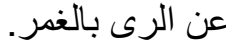

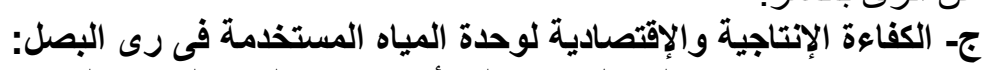

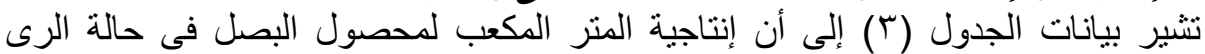

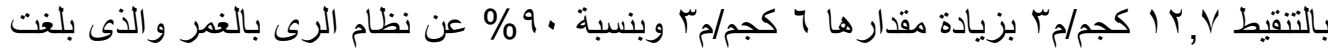

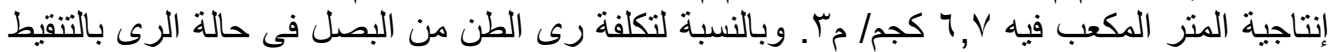

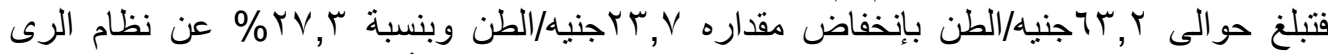

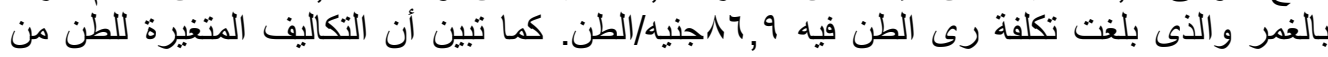

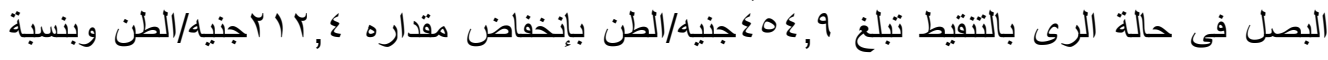

Fayoum J. Agric. Res. \& Dev., Vol. 30, No.2, July, 2016 
Vu

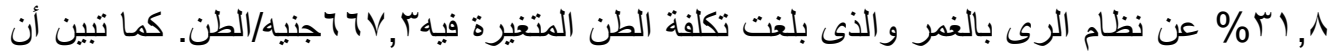

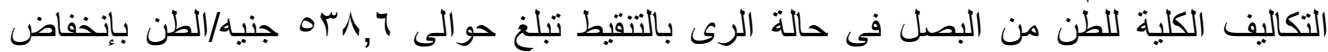

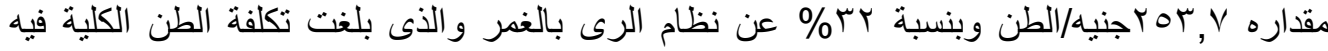

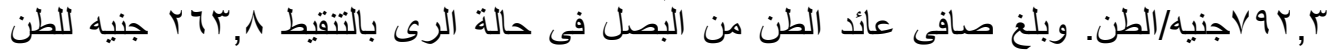

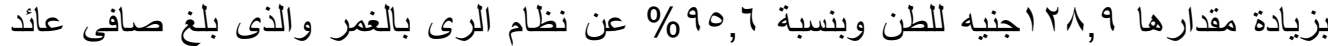

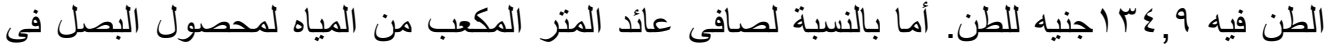

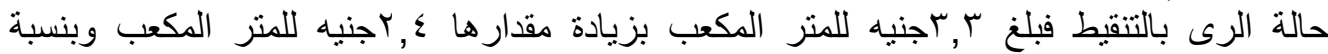

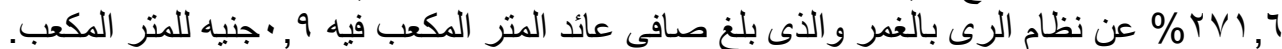

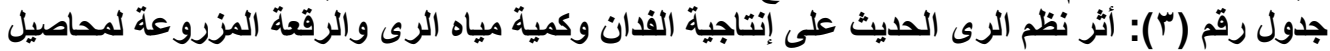

\begin{tabular}{|c|c|c|c|c|c|c|c|c|c|c|}
\hline \multicolumn{4}{|c|}{ القمح } & \multirow{2}{*}{\multicolumn{2}{|c|}{ الرى بالتنقيط }} & \multirow{2}{*}{\multicolumn{2}{|c|}{ الزى بالتنقيط }} & \multirow{2}{*}{\multicolumn{2}{|c|}{ الرى بالتنقيط الطماطم }} & \multirow{3}{*}{ المحصول } \\
\hline \multicolumn{2}{|c|}{ الرى بالرش } & \multicolumn{2}{|c|}{ الرى بالتنقيط } & & & & & & & \\
\hline$\%$ & الوفر & $\%$ & الوفر & $\%$ & الوفز & $\%$ & الوفز & $\%$ & الوفر & \\
\hline $7, \sum \Lambda$ & $\cdot, 90$ & $17, V Y$ & $r, \leqslant 0$ & $19, \leq 7$ & $r, q$ & $\sum q, r$ & 7,9 & $01, \mathrm{r} \Lambda$ & $9, r$ & الإنتاجية (طن /فدان) \\
\hline $11, r$ & ro. & r) & $\leqslant v$. & $17, \mathrm{~V}$ & $0 \leqslant Y$ & $r 1,0$ & $\leqslant 0$. & 17 & $\leqslant 0 \leqslant$ & 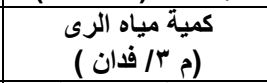 \\
\hline $1 \leqslant, r$ & $r$ & $1 \leqslant, r$ & $r$ & $1 \leqslant, r$ & $r$ & $1 \leqslant, r$ & $r$ & $1 \leqslant, r$ & $r$ & الرقعة المزروعة \\
\hline 19,9 & $\cdot, r$ & $\varepsilon \vee, q$ & $\cdot, 0$ & $\varepsilon r, 0$ & r & 9. & 7 & $\Lambda \cdot, r$ & 0,1 & 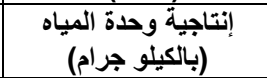 \\
\hline $10, r_{0}$ & $(1 r, 9)$ & $r \cdot, \varepsilon$ & $(\mid \wedge\rceil)$, & 17 & $(17, \wedge)$ & $r v, r$ & $(Y r, Y)$ & rr, r & $(Y \Sigma)$ & تكلفة رى الوحدة المنتجة \\
\hline$r, r$ & $\left(\wedge \vee, q^{q}\right)$ & $r q, q$ & $(1 \cdot 7, \varepsilon)$ & $r \wedge, r$ & $(Y \vee V, V)$ & $r, \wedge$ & $(Y, Y, \varepsilon)$ & ro,o & $(Y \backslash \varepsilon, \varepsilon)$ & التكاليف المتغيرة للوحدة \\
\hline $11, \leqslant 9$ & $(90, Y)$ & $r \Sigma, \cdot$ & $(1 K r, T)$ & $r ч, Y$ & $(Y \leq V)$ & re & $(Y \circ Y, Y)$ & $r 0, r$ & $(Y q \vee, Y)$ & التكاليف الكلية للوحدة \\
\hline$(00 r, \wedge)$ & $\wedge 9,1$ & $(0 \vee 0,9)$ & $9 r, \wedge$ & $I T r, r$ & TAY & 90,7 & $1 Y \wedge, q$ & $9 \wedge, \vee$ & ro.,$\wedge$ & صافى عائد الوحدة المنتجة \\
\hline$(T \leq r)$ & $\cdot, \mathrm{V}$ & $(\wedge \cdot r, q)$ & $\cdot, 9$ & $r r q, q$ & $r, r r$ & $r V I, T$ & $r, \varepsilon$ & rON, 1 & $\varepsilon, r$ & صافى عائد وحدة المياه \\
\hline
\end{tabular}

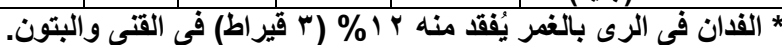

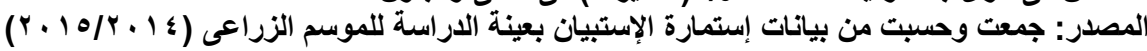

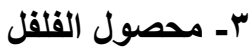

أـ أثر إستخدام نظم الرى المختلفة على بنود تكاليف إنتاج القدان من الفلقل وإيراداته:

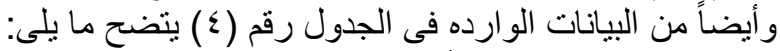

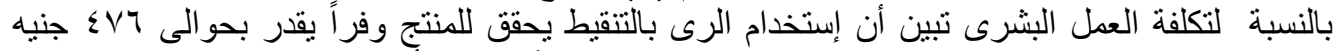

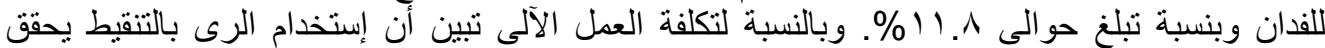

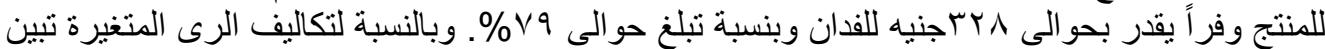

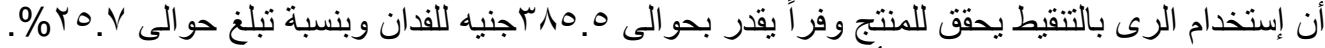

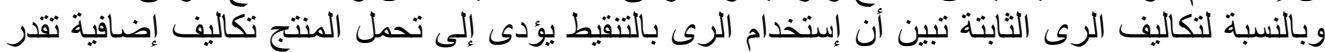

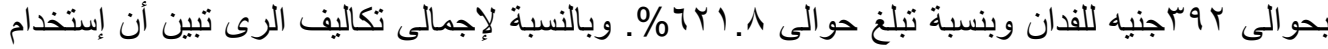

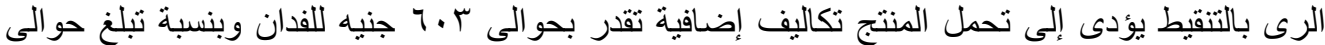
؛ . • \%. وبالنسبة للإير اد الكلى تبين أن إستخدام الرى بالتتقيط يحقق للمنتج زيادة فى الإيراد الكلى تقدر

Fayoum J. Agric. Res. \& Dev., Vol. 30, No.2, July, 2016 


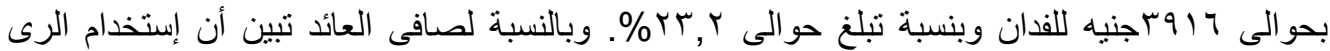

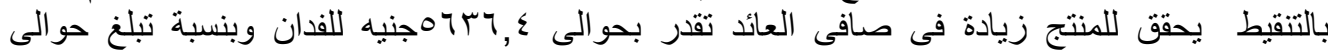

ب- التغير في الغلة الفدانية والمستخدم من مياه الرى والرقعة المزروعة لمحصول الفلفل:

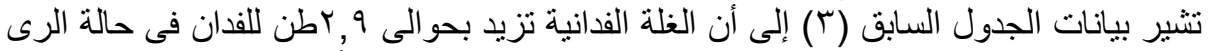

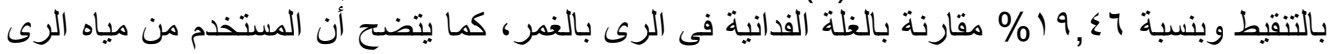

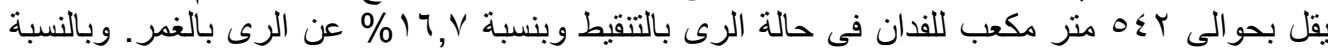

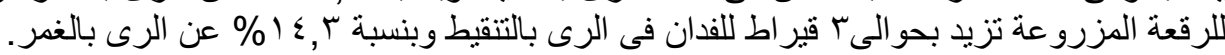

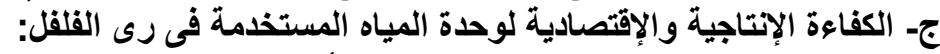

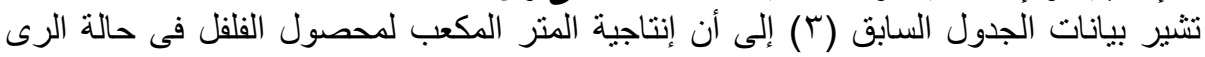

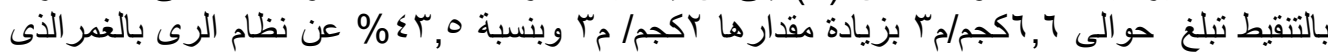

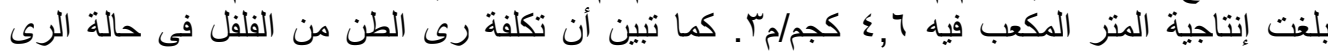

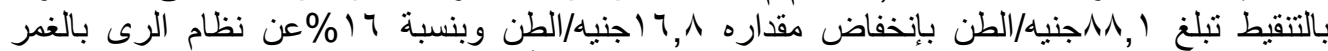

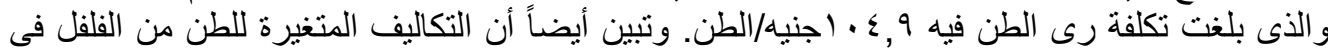

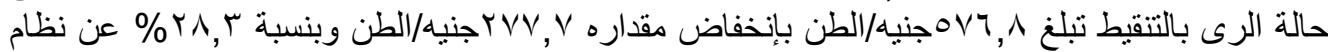

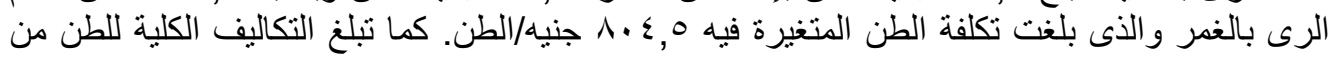

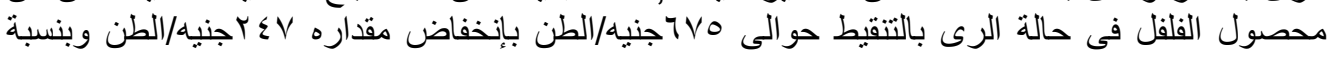

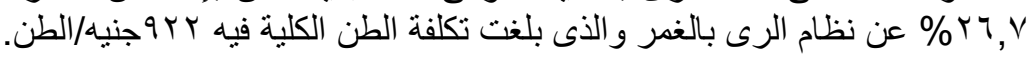

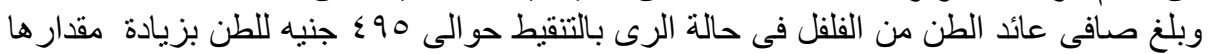

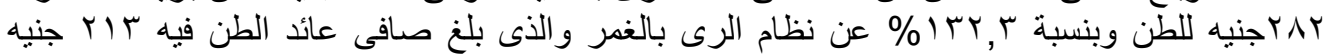

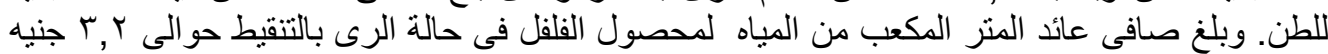

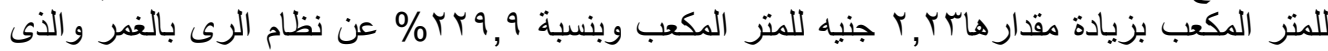

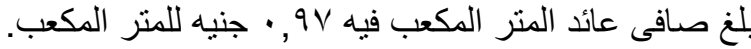

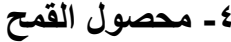
أ- أثر إستخدام نظم الرى المختلفة على بلى بنود تكاليف إنتاج الفدان من القمح وإيراداته:

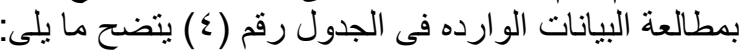

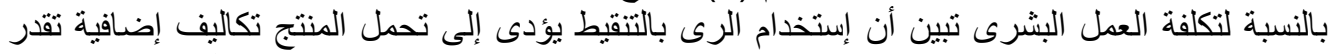

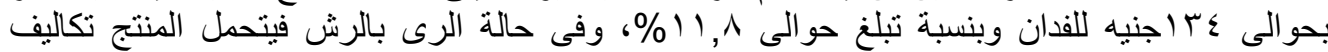

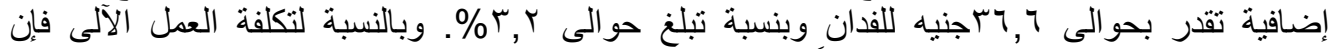

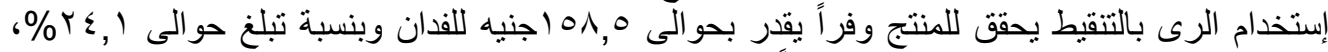

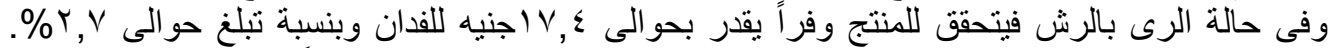

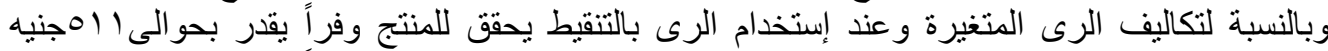

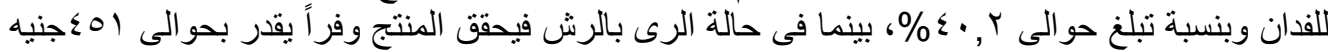

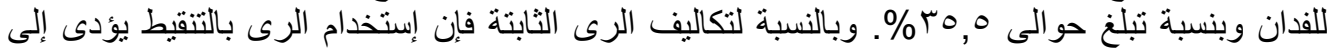

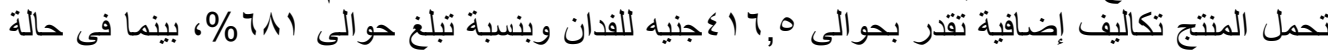

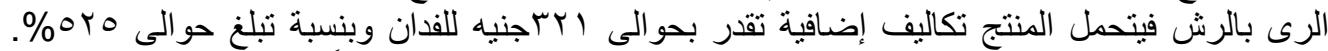

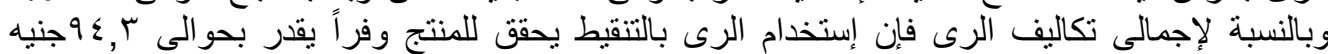

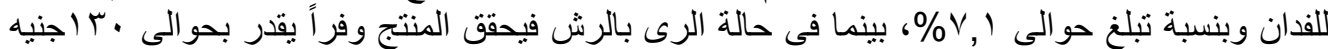

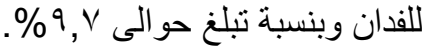
وبالنسبة للإِير اد الكلى تبين أن إستخدام الرى بالتنقيط يحقق للمنتج زيادة فى الإير اد الكلى تقدر

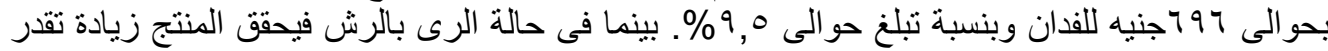

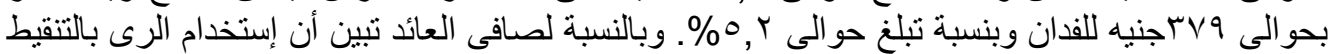

Fayoum J. Agric. Res. \& Dev., Vol. 30, No.2, July, 2016 
Vo

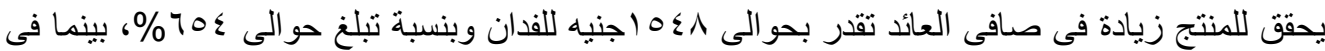

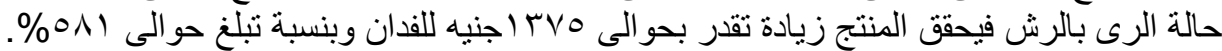

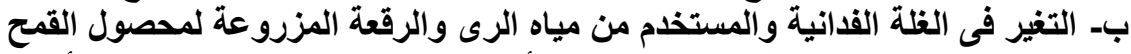

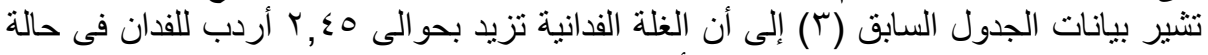

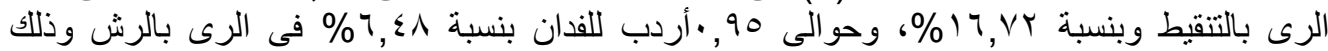

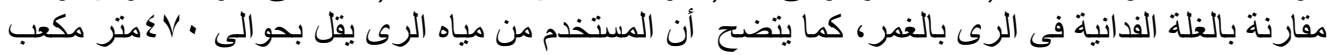

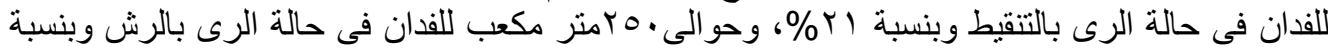

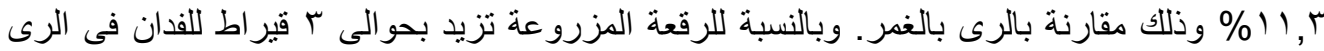

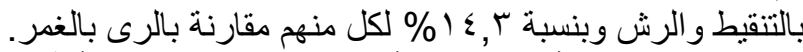

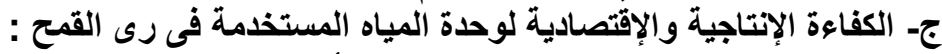

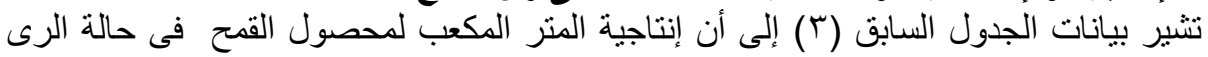

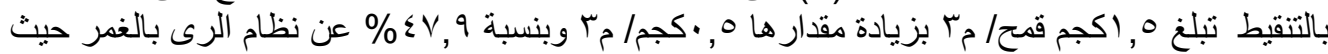

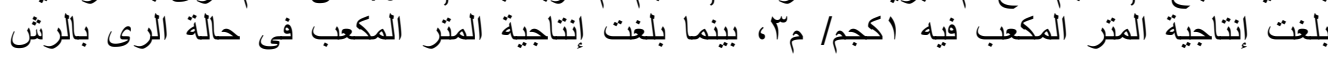

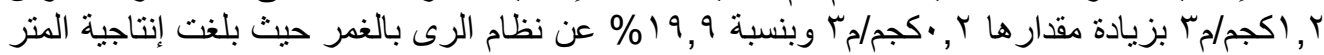

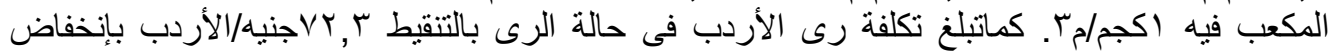

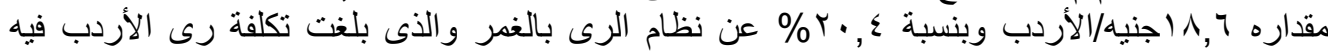

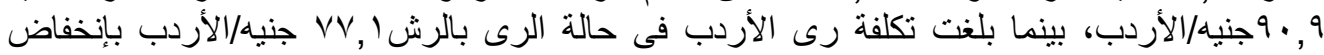

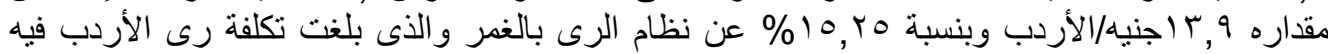

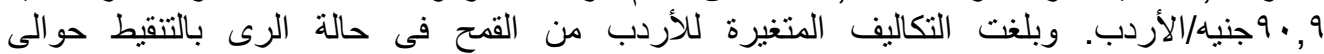

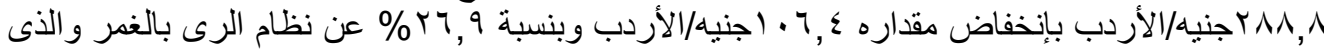

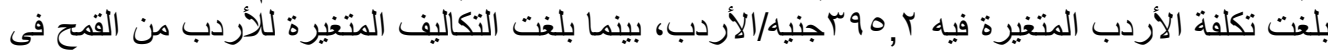

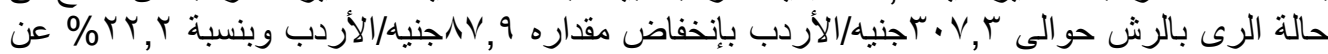

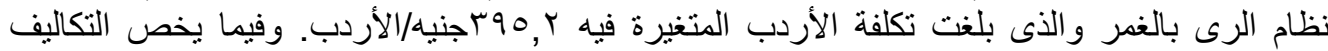

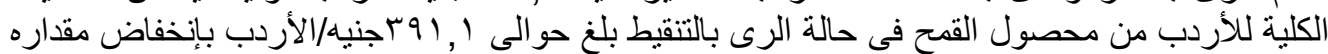

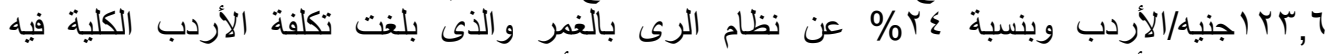

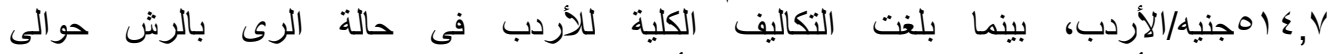

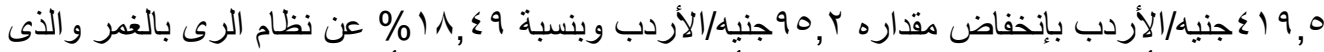

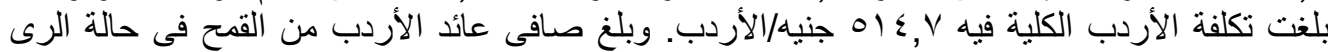

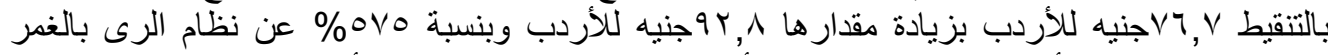

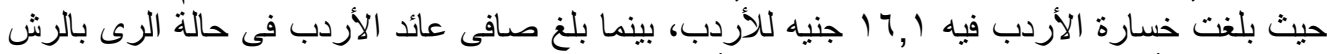

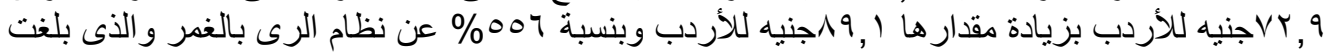

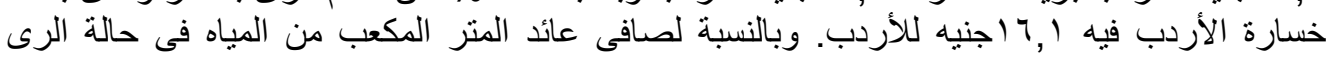

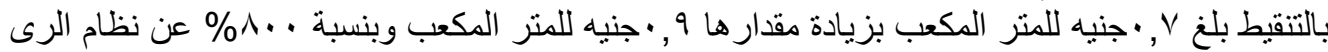

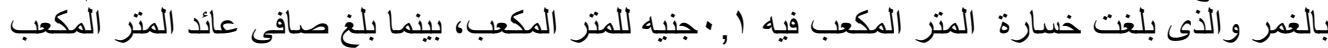

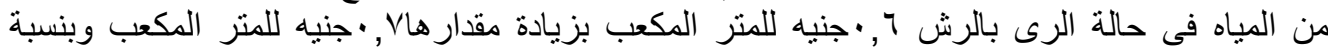

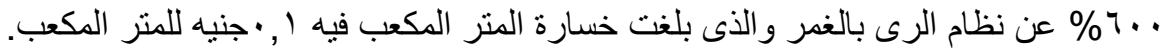
جدول رقم (ع): أثز إستخدام نظم الرى على تكاليف وإيرادات الفدان من محصول القلفل والقمح

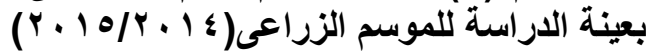

\begin{tabular}{|c|c|c|c|c|c|c|c|c|c|c|c|}
\hline \multicolumn{7}{|c|}{ القمح } & \multicolumn{4}{|c|}{ القلقل } & المحصول \\
\hline$\%$ & الرى بالتنقيط & $\%$ & (مقدار التغير) & بالتثقيط & بالرش & بالغمر & $\%$ & مقدار & بالتنقيط & بالغمر & البيان \\
\hline 11,1 & $1 \pi r, 9$ & $r, r$ & $r 4,7$ & $1 \times 79,1$ & $11 \times 1, \mathrm{~V}$ & $11 r 0,1$ & 11,1 & $(\leqslant \vee 0,9)$ & $\varepsilon \cdot r,, \wedge$ & $r 000,9$ & العمل البشرى* \\
\hline$r \leqslant, 1$ & $(101,0)$ & $r, r$ & $(I V, \varepsilon)$ & $\varepsilon 91,0$ & 749,7 & $70 \mathrm{~V}$ & $V \wedge, q$ & $(r Y \wedge, \varepsilon)$ & \&17, \& & $\Lambda \Lambda$ & العمل الآلى * \\
\hline
\end{tabular}

Fayoum J. Agric. Res. \& Dev., Vol. 30, No.2, July, 2016 


\begin{tabular}{|c|c|c|c|c|c|c|c|c|c|c|c|}
\hline$\varepsilon \cdot, r$ & $(01 \cdot, \wedge)$ & $r_{0}, 0$ & $(\leqslant 01, \cdot)$ & $V 7 \cdot, 1$ & Nr. & $|r V|$ & $r 0, Y$ & $(r \wedge 0,0)$ & $10 \ldots$ & $111 \leq, 0$ & تكاليف الرىى \\
\hline T从, & $\leqslant 17,0$ & oro & TrI & $\varepsilon V Y, T$ & rAr, & 7,1 & 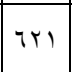 & $r 91,1$ & Tr & $\leqslant 0 \leqslant, V_{0}$ & تكاليف الرىى \\
\hline$v, 1$ & $(9 \leqslant, r)$ & $9, Y$ & $\left.\left(1 \Upsilon^{\prime},\right\urcorner\right)$ & $\mid r \mu v, \wedge$ & $M r \cdot r, O$ & ITr, & $\cdot, \varepsilon$ & $7, r$ & $107 \pi$ & $1079, r$ & إجمالى تكاليف \\
\hline $0 \wedge, \wedge$ & $(\Gamma \wedge 1,1)$ & $\varepsilon, 7$ & $r q, r$ & Y77, 7 & $T V V, \varepsilon$ & $T \leqslant V, V$ & $\wedge \leq, \wedge$ & $($ (Tr,,$T)$ & 77r, & $r \leqslant$. & السماد البلاى \\
\hline 01,1 & $(097, v)$ & $0 \leqslant, 9$ & $(7 r, q)$ & $007, r$ & or. & $110 r, 9$ & $07, V$ & $(9 \leq 9)$ & $17 V \leqslant, 0$ & VYo,o & الأسمدة الأزوتية \\
\hline 90,1 & $(Y \vee \neg, Y)$ & 10,0 & $(\varepsilon 0)$ & $1 \leqslant, 1$ & $r \leq 0, r$ & $r q \cdot r$ & $q v, v$ & $(09 \leqslant, 9)$ & 7.9 & $1 \leq, 11$ & القوسفاتية \\
\hline- & Tor, , & - & $\cdot, \cdot$ & 70r,1 & . & . & $1 \ldots$ & 90,0 & 90,0 & 191 & لغناصر الصغرى \\
\hline - & - & - & - & - & - & - & & $\langle\wedge 1, \varepsilon$ & - & $\wedge \wedge 1, \varepsilon$ & الاسبمدة \\
\hline$r \wedge, 0$ & $(Y \leqslant, \wedge)$ & $O V, \varepsilon$ & $(\leqslant १, \wedge)$ & $T r$ & $r v$ & $\Lambda \neg, \mathrm{V}$ & 7,0 & ov & $\Lambda \Lambda$. & $9 \mathrm{Tr}$ & المبيدات \\
\hline$r r, q$ & $(170, \mathrm{~V})$ & $r \Lambda, r$ & $(1 \wedge 7,0)$ & TYT & $r \cdot r, I V$ & $\varepsilon \wedge \lambda, \vee$ & $\varepsilon$ & $(\wedge r, \Sigma)$ & $r .00$ & $19 Y Y, 7$ & التقاوى \\
\hline $1 \varepsilon, V$ & $(101,9)$ & IV,r & $(997, \varepsilon)$ & $\leqslant 9 \uparrow \wedge, \wedge$ & $\leqslant \vee 9 \leqslant, r$ & $\circ \vee q \cdot, v$ & $1 \leqslant, \varepsilon$ & $(\mid \vee Y \cdot, \Sigma)$ & $11911, \varepsilon$ & $1 . \times 71$ & إجمالى التكاليف \\
\hline $11, r$ & $(101,9)$ & $1 T, r$ & $(997, \varepsilon)$ & $74 \wedge \lambda, \wedge$ & $70 \leqslant \leqslant, r$ & $v 0 \leq \cdot, v$ & $1 r, 0$ & $(I \vee Y \cdot, \Sigma)$ & $1 T V T \Lambda, \varepsilon$ & $1 r \cdot 11$ & إجمالى التكاليف \\
\hline 9,0 & 790,1 & $0, Y$ & $r \vee \wedge, \wedge$ & $\lambda \ldots$ & VฯAT & $V \Psi \cdot \varepsilon$ & $Y r, Y$ & 4917 & $1791 \leq$ & T.AT. & الإيراد الكلى \\
\hline $70 \leqslant$ & $10 \leqslant \mathrm{~V}, \mathrm{~V}$ & 011 & $1 r v 0, r$ & $1 \pi 11, r$ & $11 r \wedge, 7$ & Yr4.0- & IVV & 0744,5 & $r, 1 \vee 4$ & $\wedge, \wedge \backslash \uparrow$ & صافى العائد \\
\hline
\end{tabular}

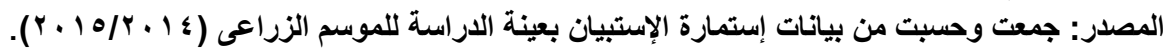

ثانياً: الأثر الإقتصادى لنظم الرى المختلفة على محاصيل الاراسة فى بنى سويف وعلى مستوى

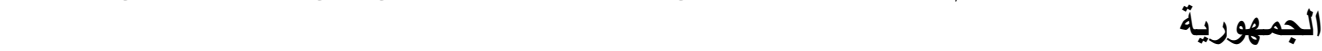
سوف يتم تقدير أثر نظم الرى المختلفة على ترشيد مياه الرى والتوسع فى المساحة

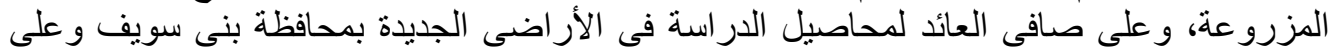

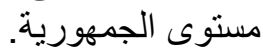

(1) أثر إستخدام نظم الرى المختلفة على ترشيد مياه الرى والتوسع فى المساحة المزروعة :

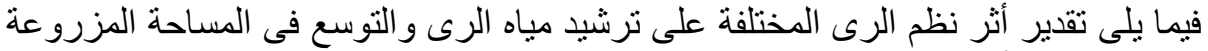

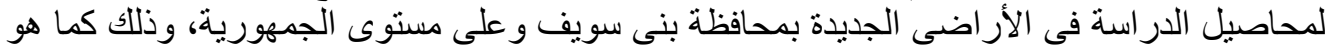

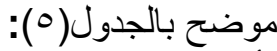
(أ) (الطماطم بالجنا

يؤدى إستخدام نظام الرى بالتتقيط إلى خفض الإستهلاك المائى للفدان من محصول الطماطح

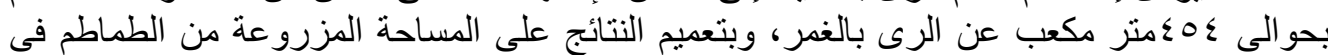

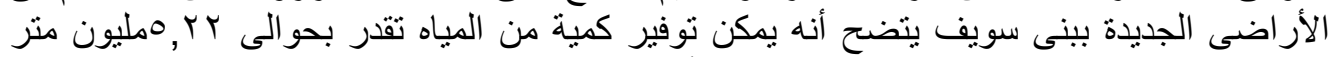

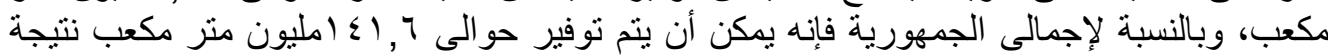

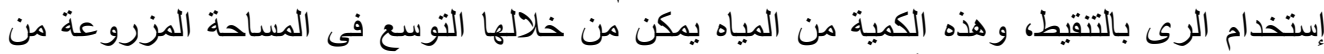

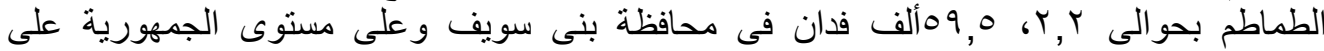

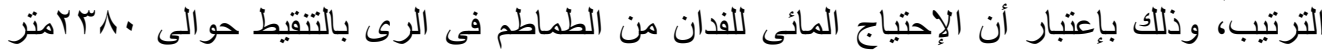

Fayoum J. Agric. Res. \& Dev., Vol. 30, No.2, July, 2016 
VV

يؤدى إستخدام نظام الرى بالتنقيط إلى خفض الإستهلاك المائى للفدان من محصول البصل البكل

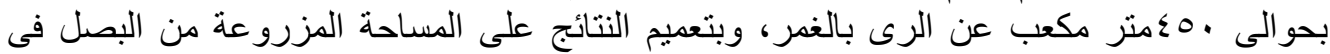

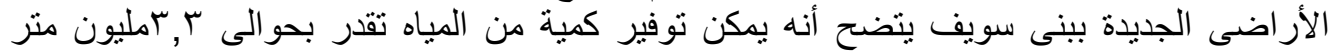

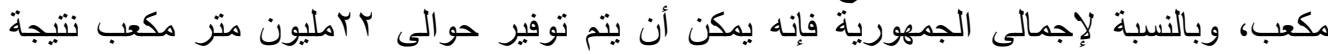

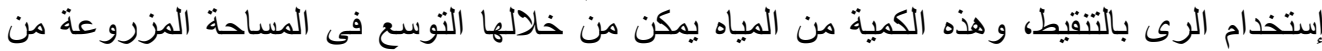

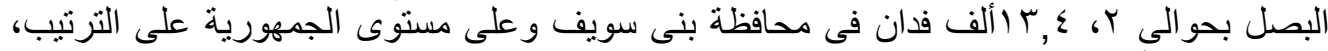

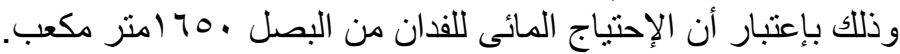

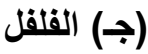

يؤدى إستخدام نظام الرى بالتنقيط إلى خفض الإستهلاك المائى للفدان من محصول الفئل الفلفل

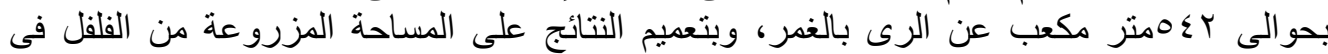

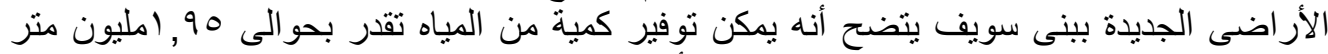

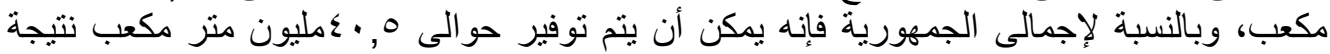

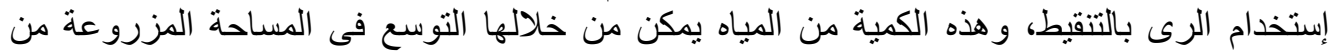

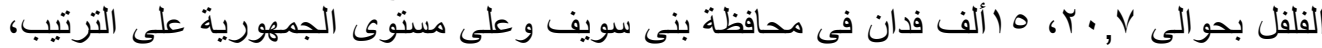

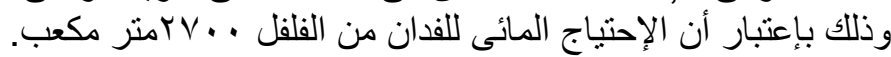

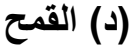

يؤدى إستخدام نظام الرى بالتنقيط إلى خفض الإستهلاك المائى للفدان من محصول القمح

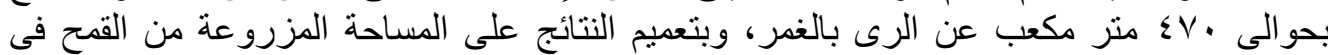

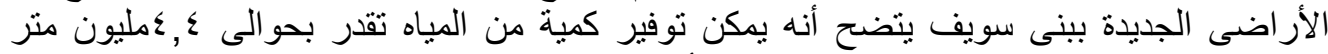

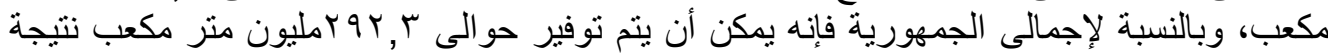

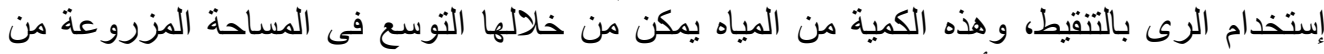

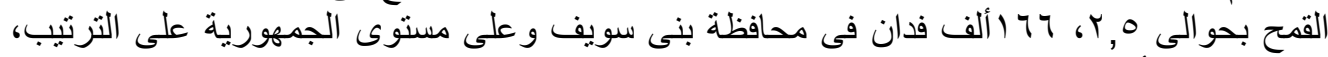

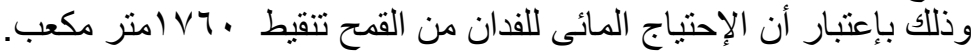

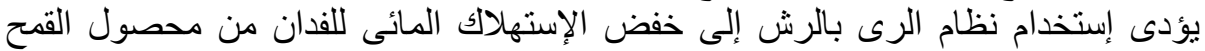

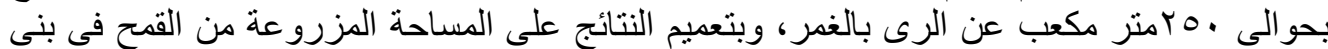

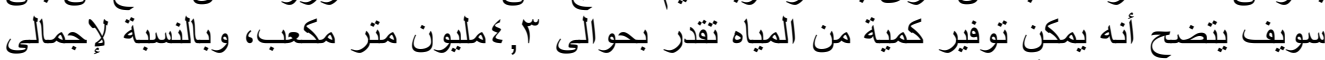

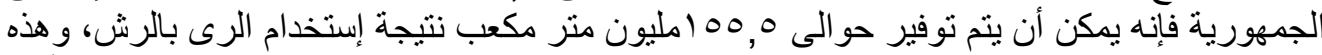

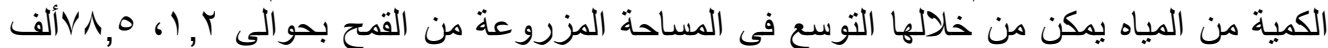

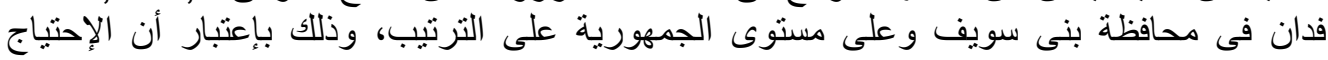

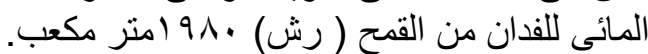

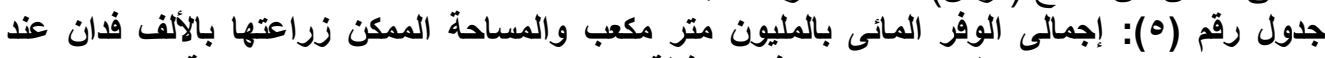

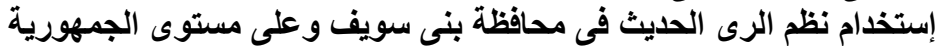

\begin{tabular}{|c|c|c|c|c|c|}
\hline \multicolumn{2}{|c|}{ المساحة الممكن زراعتها } & \multicolumn{2}{|c|}{ إجمالى الوفز فى كمية المياه } & \multirow{2}{*}{ اللوفر فى المياه } & \multirow[t]{2}{*}{ المحصول } \\
\hline الجمهورية & بنى سويف & الجمهورية & بنى سويف & & \\
\hline 09,0 & $r, r$ & $1 \leqslant 1,7$ & $0, Y Y$ & $\cdot, \leqslant 0 \leqslant$ & الطماطم(1) \\
\hline $1 \%, \varepsilon$ & $r$ & rY & $r, r$ & $\cdot, \leqslant 0$ & البصل(r) \\
\hline 10 & $\cdot, \mathrm{VY}$ & $\varepsilon \cdot, 0$ & 1,90 & $\cdot, 0 \leq Y$ & القلفل(r) \\
\hline 179 & $r, 0$ & $r q r, r$ & $\varepsilon, \varepsilon$ & $\because \leqslant V$. & القمح تنقيط(ع) \\
\hline$\vee \wedge, \bullet$ & $1, r$ & 100,0 & $\varepsilon, r$ & 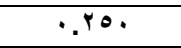 & القمح رش \\
\hline
\end{tabular}

Fayoum J. Agric. Res. \& Dev., Vol. 30, No.2, July, 2016 


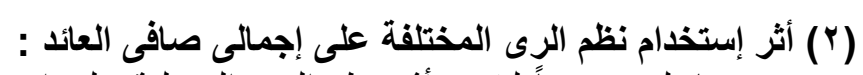

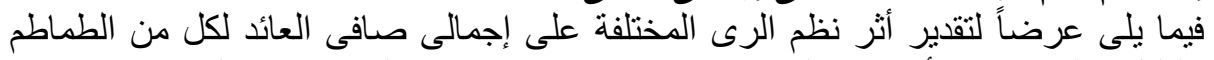

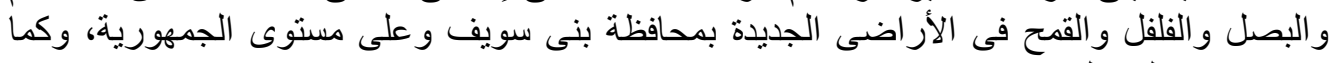

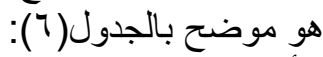
(أ) الطماطم بوطن

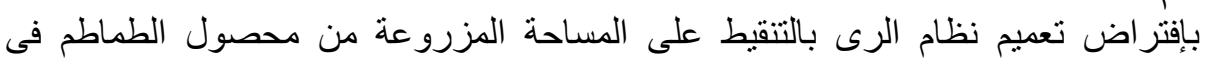

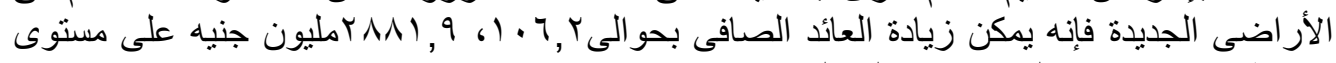

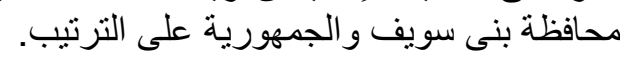
(ب) البصل

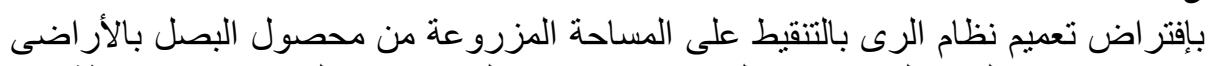

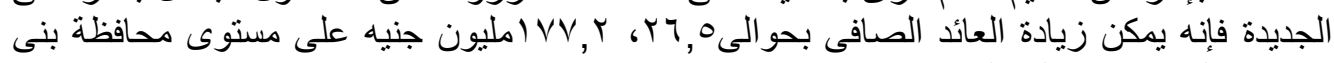
سويف والجمهورية على الترتيب. (ج) (القلقل

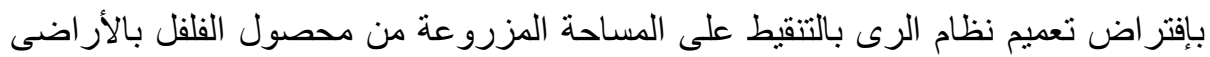

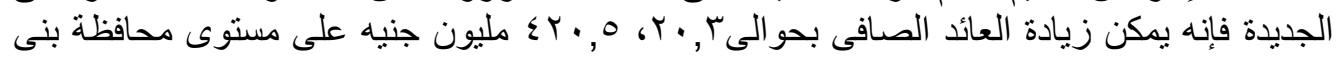
سويف والجمهورية على الترتيب. (د) القمح

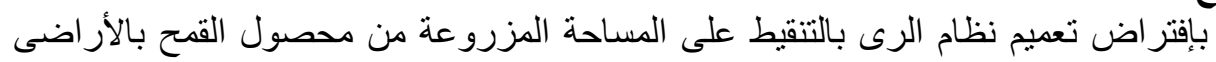

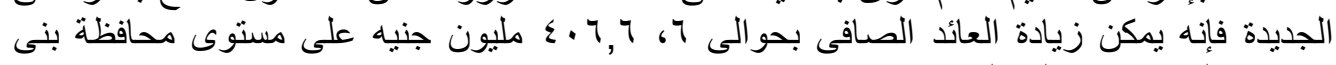
سويف و الجمهورية على الترتيب.

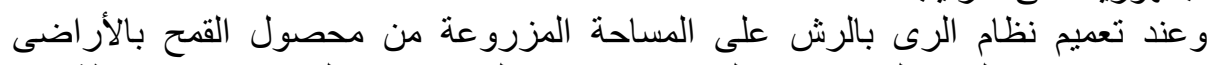

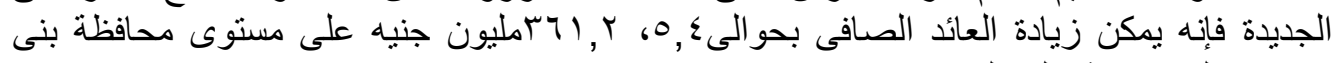

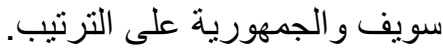
جدول رقم (†): إجمالى الزيادة فى صافى العائد لمحاصيل الدراسة عند إستخدام نظم الرى الحديث

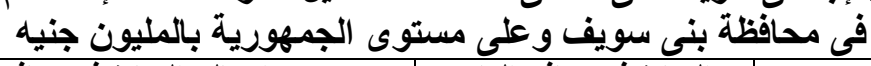

\begin{tabular}{|c|c|c|c|}
\hline \multicolumn{2}{|c|}{ إجمالى الزيادة فى صافى العائد } & \multirow{2}{*}{ الزيادة في صافى العائد } & \multirow[t]{2}{*}{ المحصول } \\
\hline الجمهورية & بنى سويف & & \\
\hline$r \wedge \Lambda 1,9$ & $1.7, Y$ & QTrV & الطماطر \\
\hline$I V V, r$ & $r 7,0$ & TTE & البصل \\
\hline$\varepsilon r \cdot, 0$ & $r \cdot, r$ & 0747 & القلفل \\
\hline$\varepsilon \cdot 7,7$ & 7 & $70 \leqslant$ & القمح تثقيط \\
\hline r4ו, r & $0, \xi$ & $0 \lambda 1$ & القمح رش \\
\hline
\end{tabular}

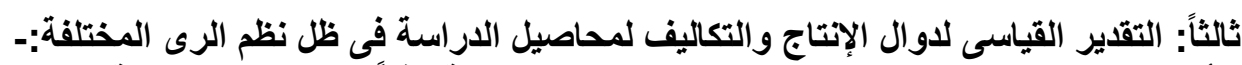

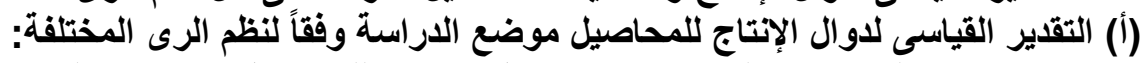

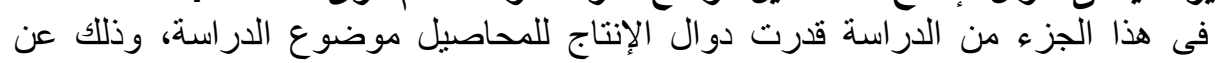

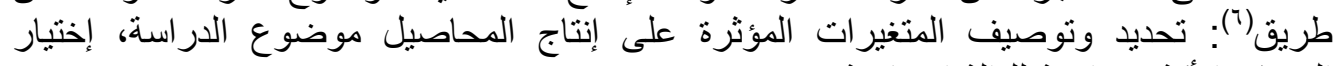

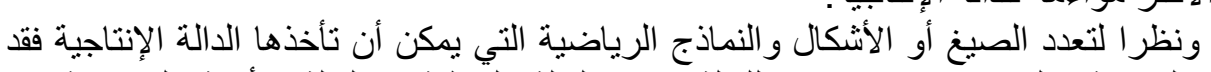

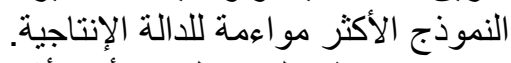

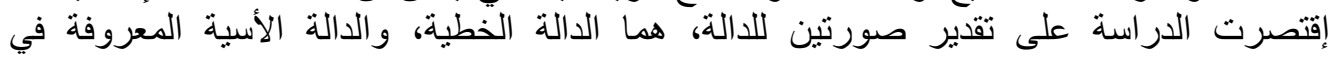

Fayoum J. Agric. Res. \& Dev., Vol. 30, No.2, July, 2016 
$\vee q$

التطبيقات الإقتصادية باسم دالة كوب دوجلاس. حيث : ص^هـ = الكمية التقديرية للإنتاج من المحصول موضع الإراسة بالطن أو الأردب.

س، هـ = عدد ساعات الرى، سبرنه = كمية مياه الردى، سبهـ = كمية السماد البلدى بالمقطورة

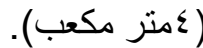

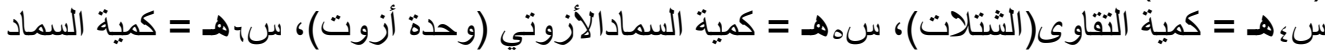

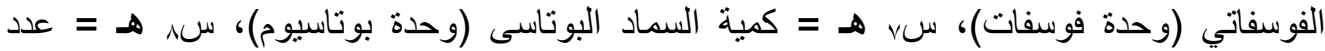

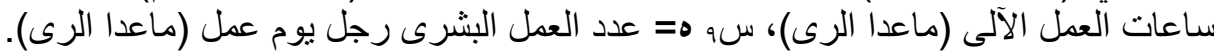

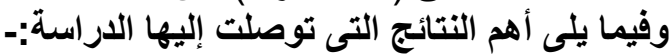

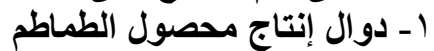

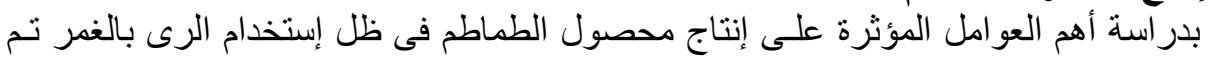

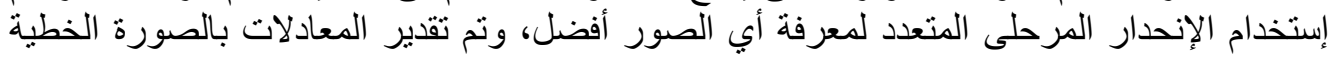

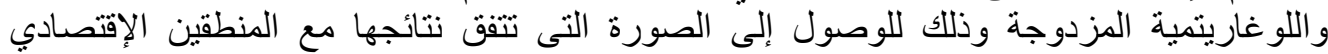

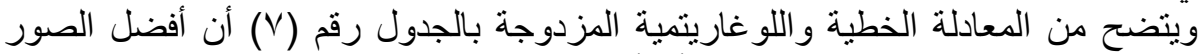

و الإحصائي.

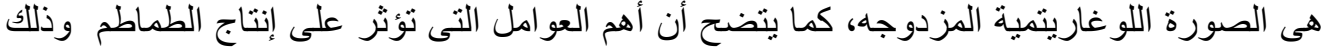

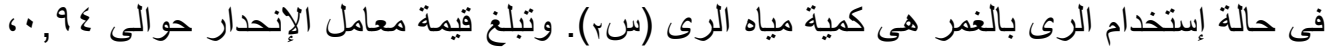

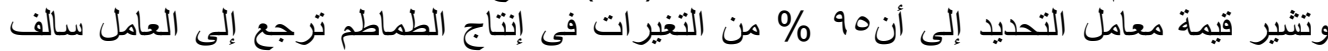

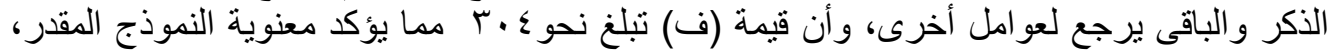

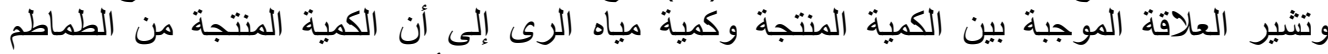

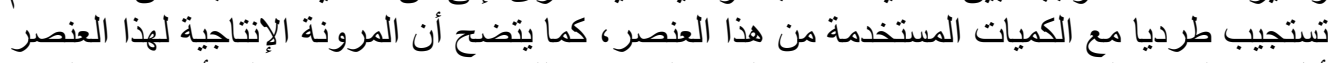

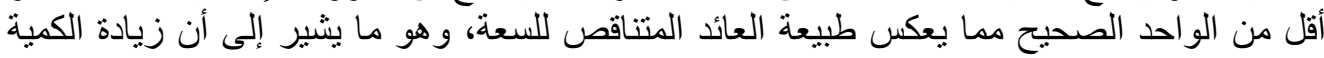

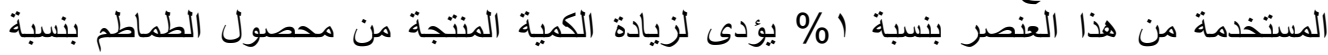

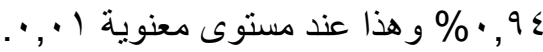

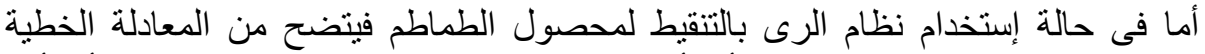

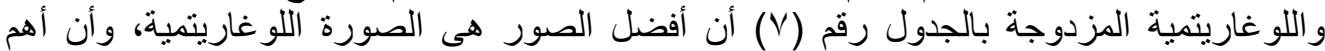

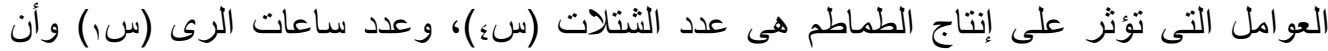

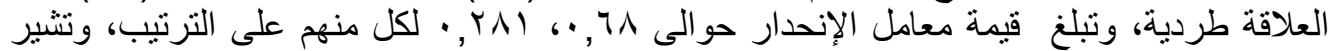

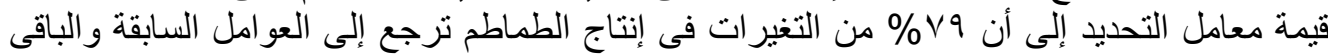

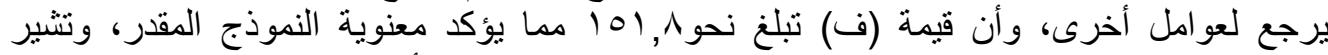

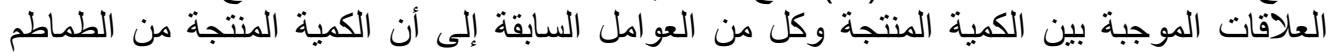

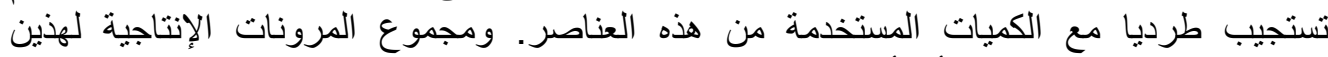

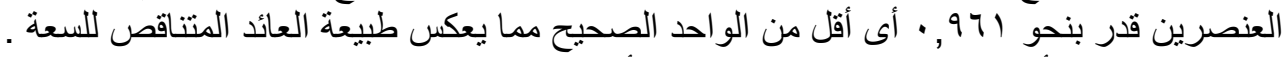

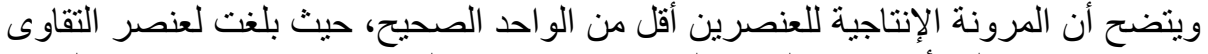

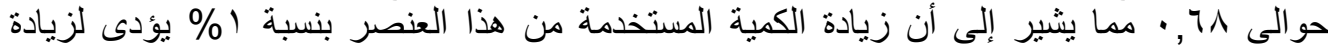

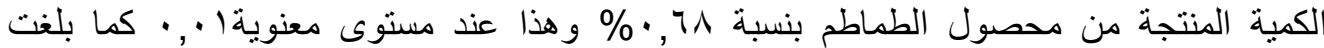

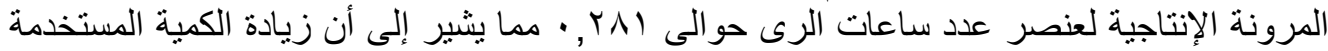

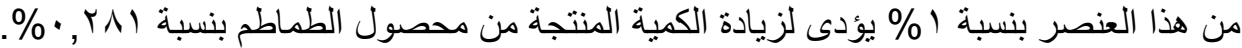
r- بوال إنتاج محصول البصل البصل

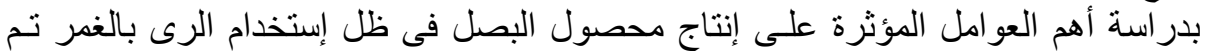

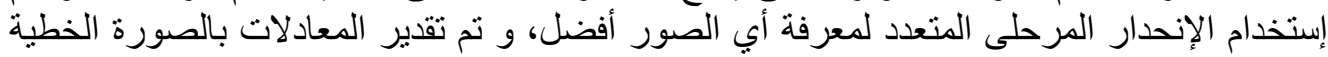

Fayoum J. Agric. Res. \& Dev., Vol. 30, No.2, July, 2016 
$\Lambda$.

و اللوغاريتمية المزدوجة وذللك للوصول إلى الصورة التى تتفق نتائجها مع المنطق الإقتصادي ويتضح من المعادلة الخطية و اللوغاريتمية المزدوجة بالجدول رقم (V) أن أفضل الصور

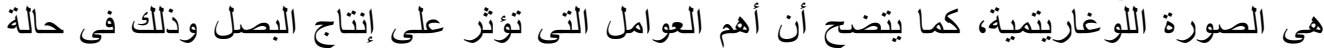

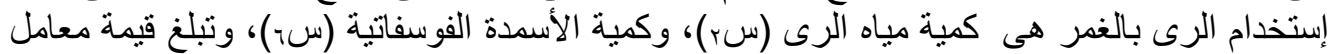

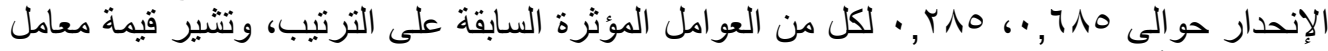

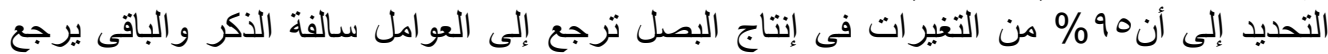

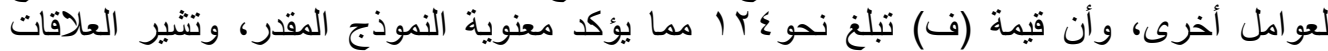

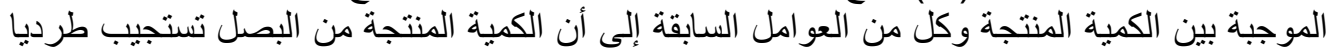

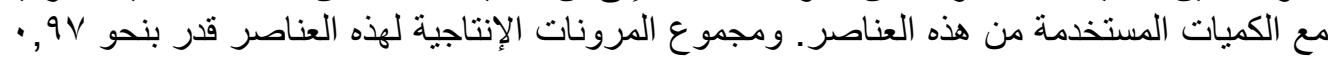

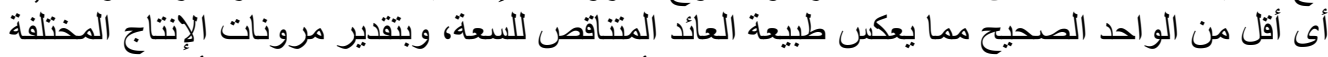

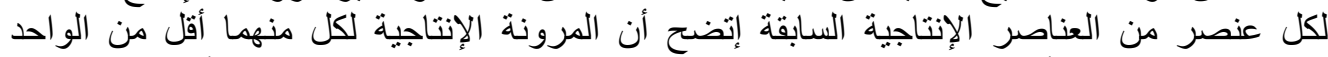

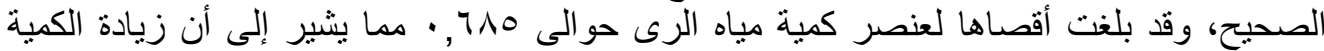

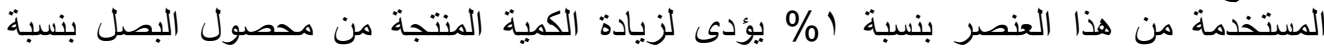

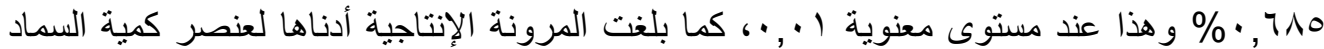

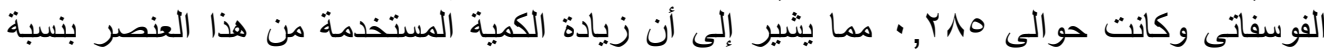

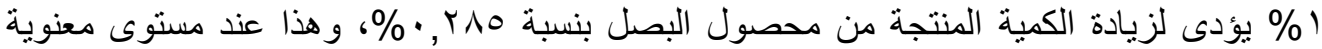
$\cdot \cdot \cdot 1$

أما فى حالة إستخدام نظام الرى بالتنقيط لمحصول البصل فيتضح من المعادلة الخطية

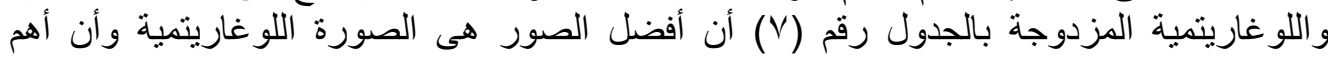

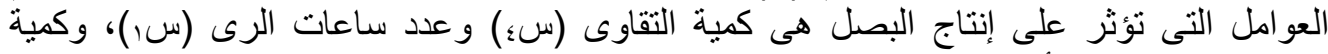

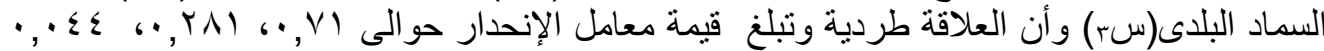

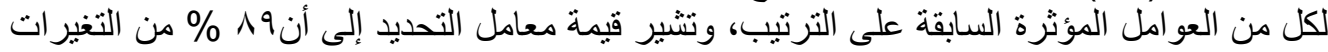

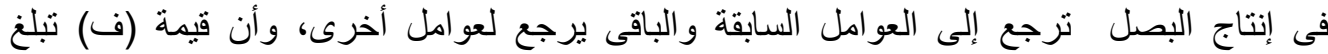

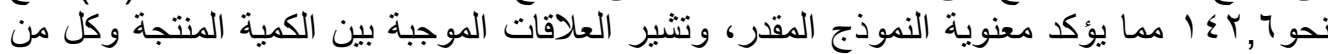
العو امل السابقة إلى أن الكمية المنتجة من البصل تستجيب طرديا مع الكميات المستخدمة من هذه الكناه

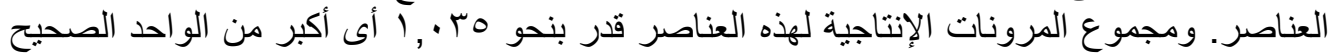
مما يعكس طبيعة العائد المتز ايد للسعة.

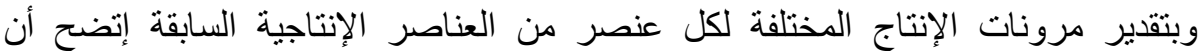

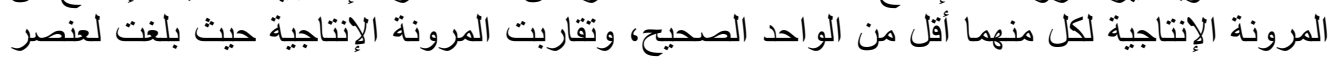

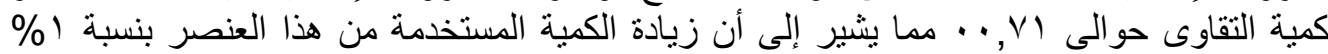

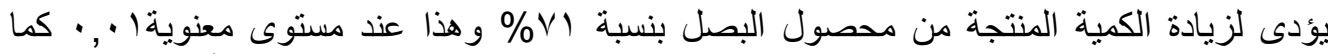

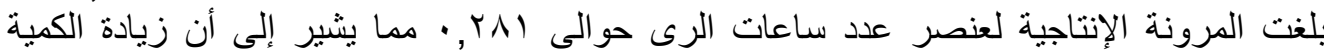

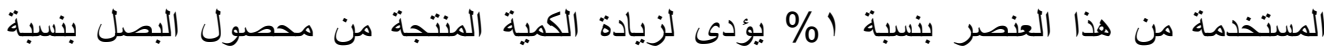

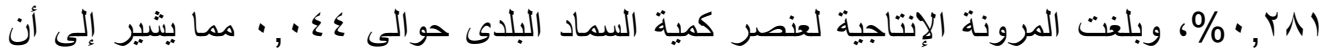

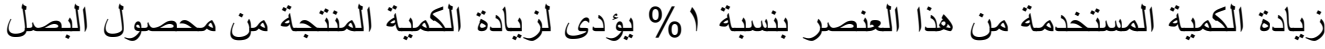
بنسبة بـ دوال إنتاج محصول الفلقة بدراسة أهم العوامل المؤثرة على إنتاج محصول الفلفل فى ظل إستخدام الرىى بالغمر تم إستخدام الإنحدار المرحلى المتعدد لمعرفة أب الصور أفضل، و تم تقدير المعادلات بالصورة فلت الخطية

Fayoum J. Agric. Res. \& Dev., Vol. 30, No.2, July, 2016 
1)

و اللوغاريتمية المزدوجة وذلك للوصول إلى الصورة التى تتفق نتائجها مع المنطق الاقتصـادي

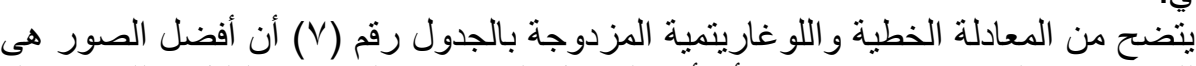

و والإحصائي.

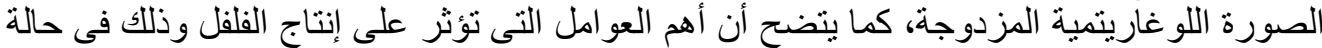

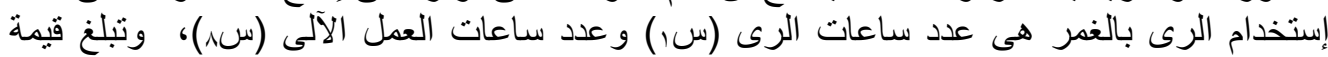

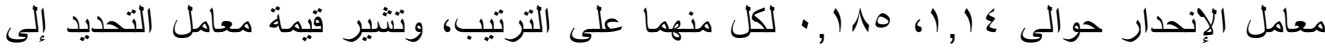

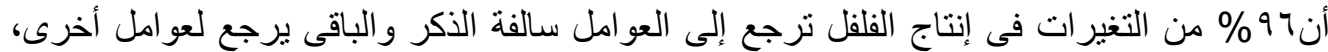

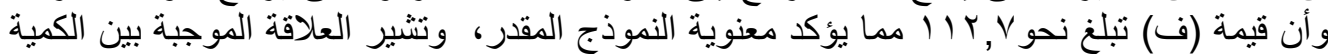

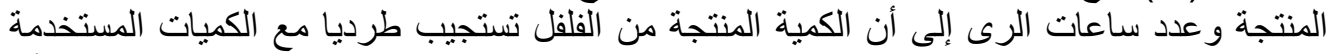

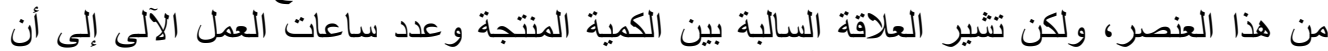

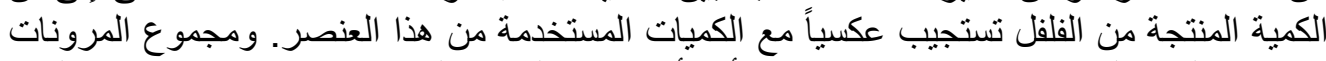

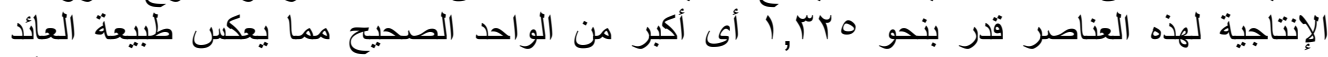

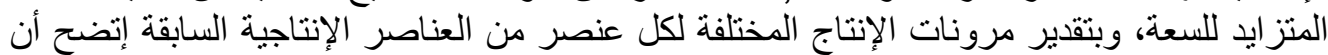

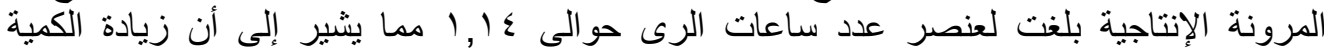

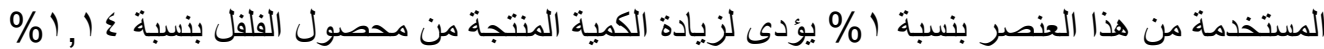

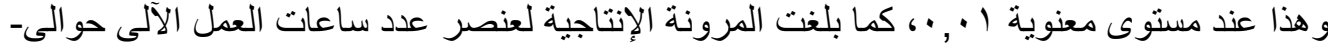

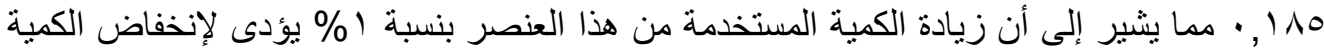

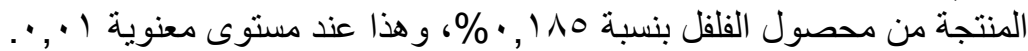

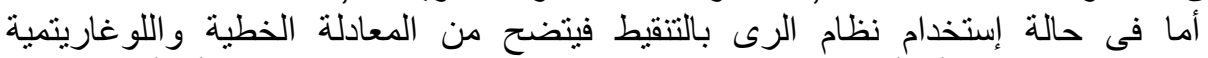

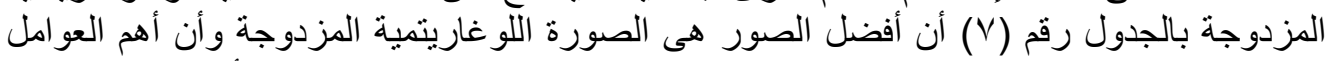

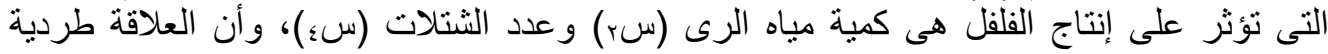

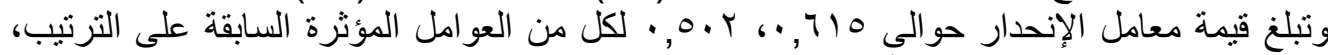

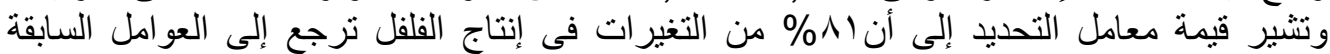

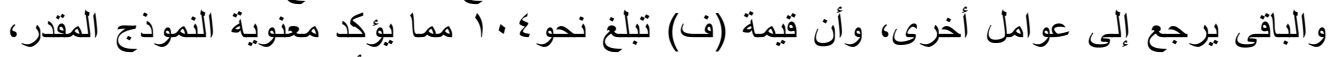

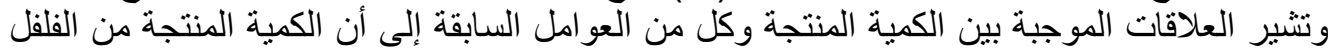

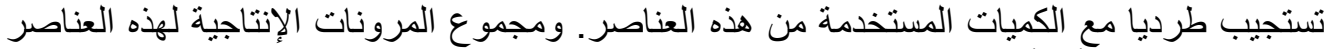

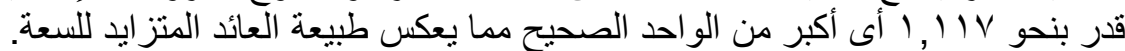

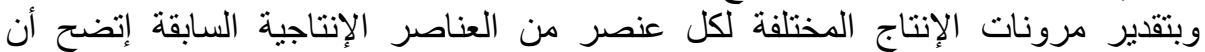

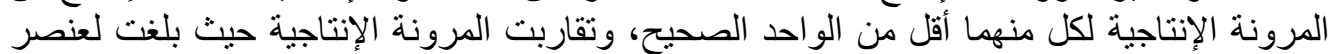

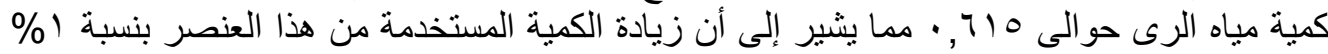

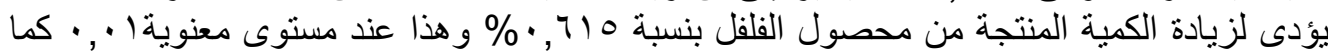

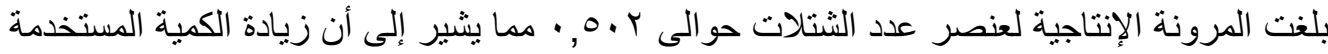

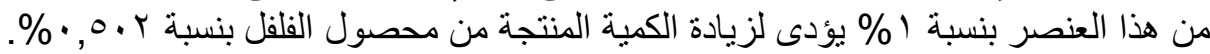

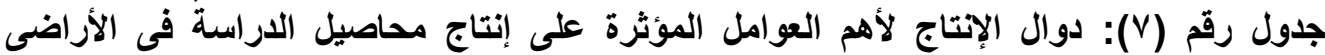

\begin{tabular}{|c|c|c|c|c|c|}
\hline \multirow{3}{*}{ ف ف } & \multirow{3}{*}{$\frac{\text { ru }}{r, \text { va }}$} & \multicolumn{4}{|c|}{ الجديدة بمحافظة بنى سويف } \\
\hline & & 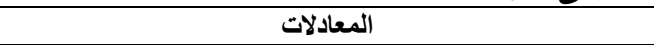 & 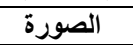 & 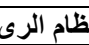 & 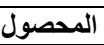 \\
\hline & & 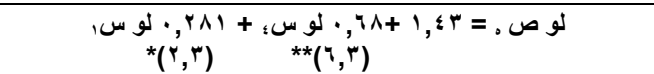 & ل الوزاريتمى & تنقيط & 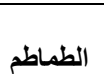 \\
\hline$r \cdot \varepsilon$ & $\cdot, 90$ & 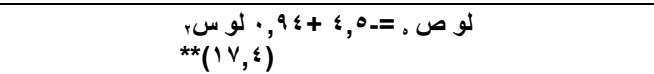 & 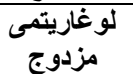 & غمر & \\
\hline $1 \leqslant 7$ & $\cdot, \wedge 9$ & لو ص . . & ل الوزاريتمى & تنقيط & البصل \\
\hline
\end{tabular}

Fayoum J. Agric. Res. \& Dev., Vol. 30, No.2, July, 2016 
$\Lambda r$

\begin{tabular}{|c|c|c|c|c|c|}
\hline $\mid r \varepsilon$ & $\cdot, 90$ & 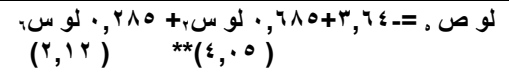 & لوزاريتمى لوز & غمر & \\
\hline $1 \cdot \varepsilon$ & $\cdot, \wedge 1$ & لو ص . = - = & لوزاريتمى لوز & تنقيط & \multirow{2}{*}{ القلقل } \\
\hline $11 r$ & $\cdot 97$ & 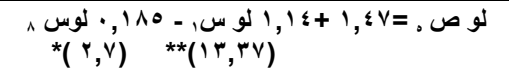 & لوزاريتمى مزدج & غمر & \\
\hline$\leqslant 79,7$ & $\cdot, 9 \leq$ & 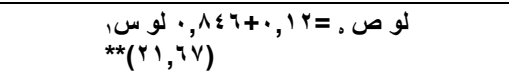 & ل الوغاريتمى مزدوج & غمر & \multirow{3}{*}{ لقح } \\
\hline 191 & $\cdot, 97$ & 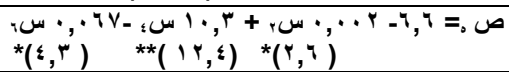 & خطى متعدد & تنقيط & \\
\hline$r r q, V$ & $\cdot, 9 \varepsilon$ & لو ص . =و = & لوزاريتمى لوز & رش & \\
\hline
\end{tabular}

المصدر: جمعت وحسبت من بيانات إستمارة الإستبيان بعينة الدراسة بمحافظة بنى سويف

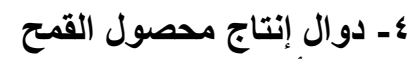

بدراسة أهم العو امل المؤثرة على إنتاج محصول القمح فى ظل إستخدام الرى بالغمر تم إستخدام

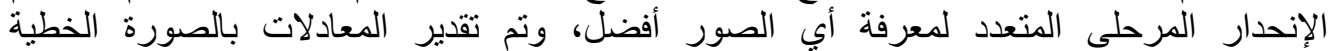

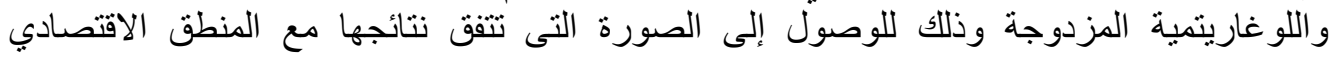
و الإحصائي.

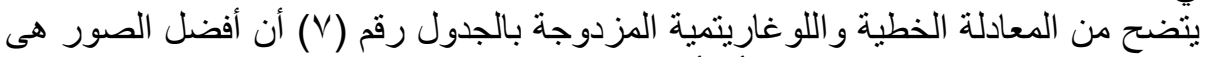

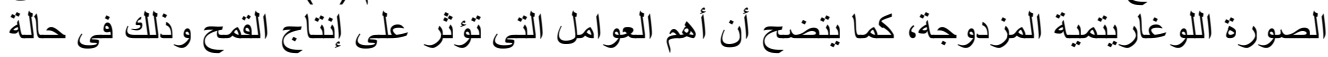

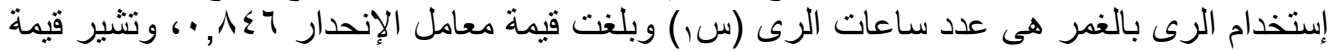

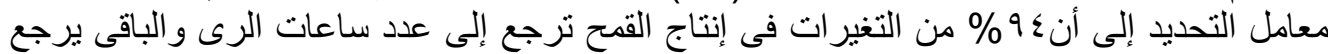

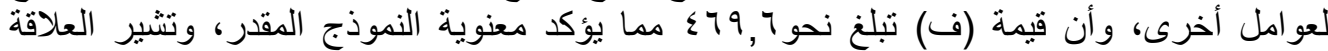

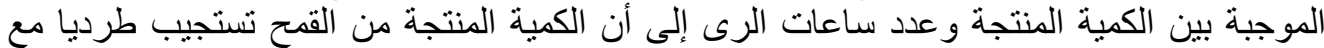

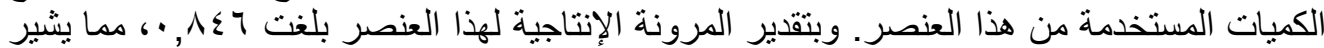

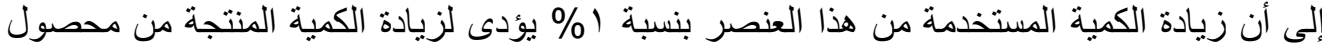

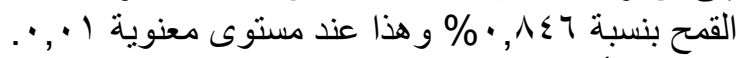

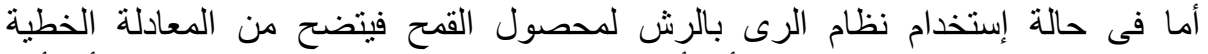

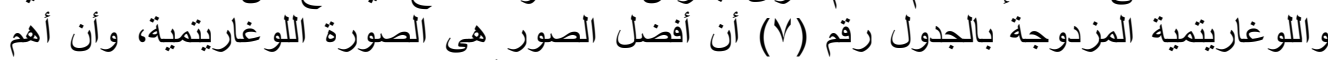

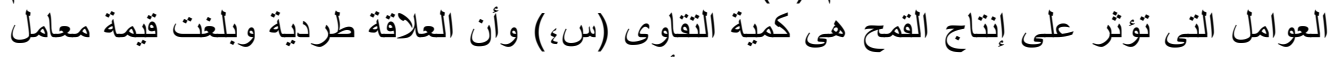

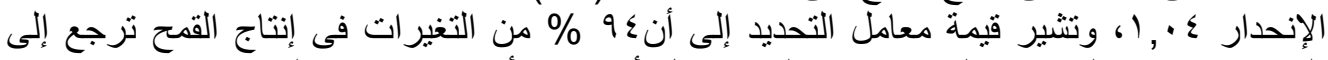

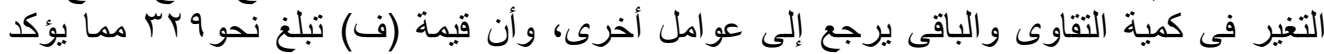

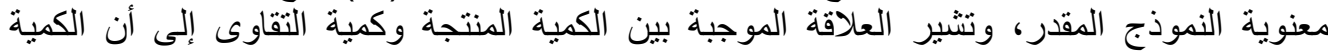

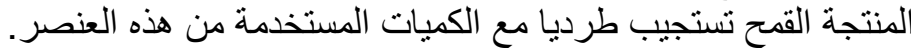

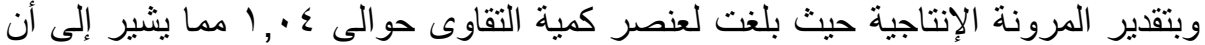

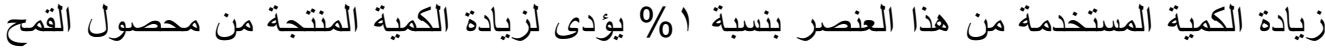

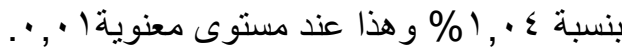

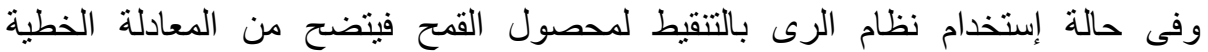

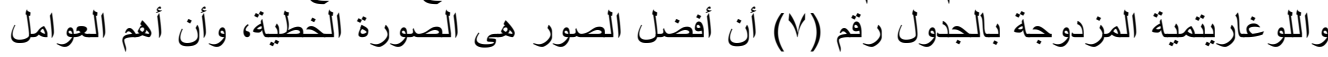

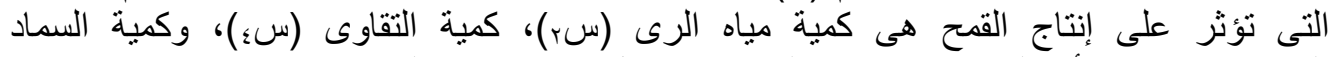

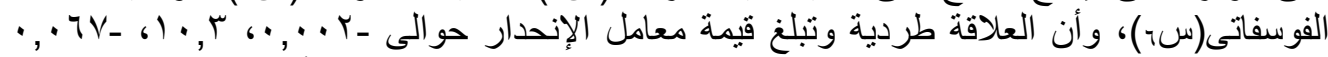

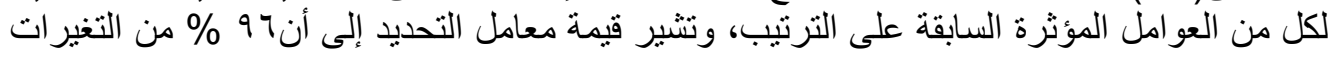

Fayoum J. Agric. Res. \& Dev., Vol. 30, No.2, July, 2016 
فيى إنتاج القمح ترجع إلى التغير فى العوامل السابقة والباقى يرجع إلى عوامل أخرى، وأن قيمة (ف)

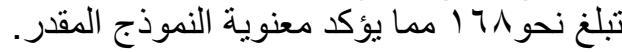

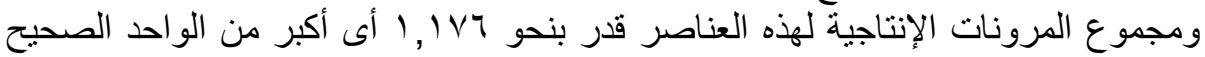

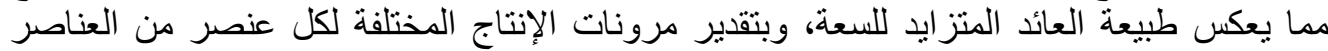

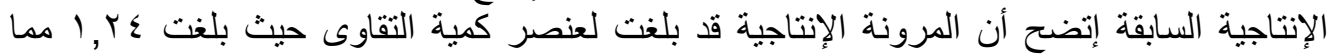

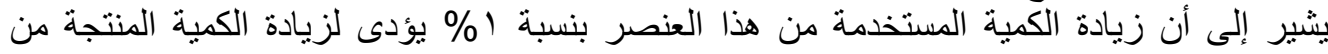

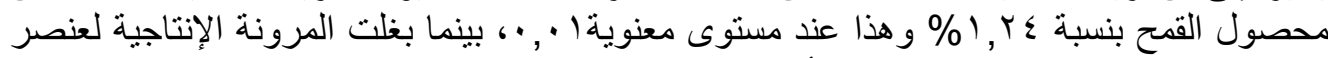

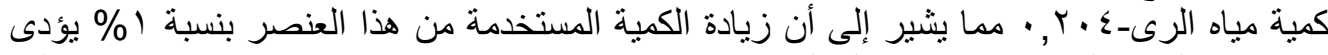

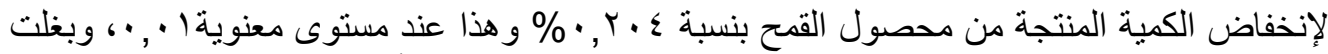

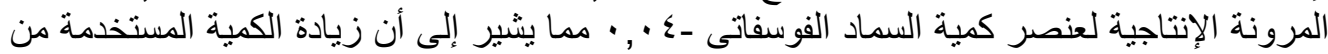

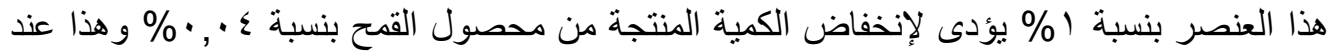

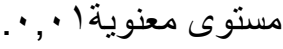

(ب) التقدير الإحصائى لدوال التكاليف لمحاصيل الاراسة وفقا لنظم الرى المختلفة:

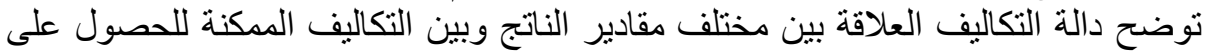

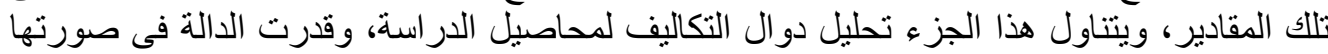

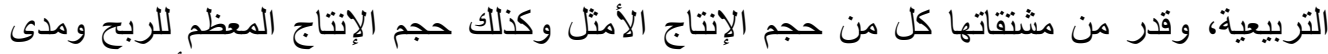

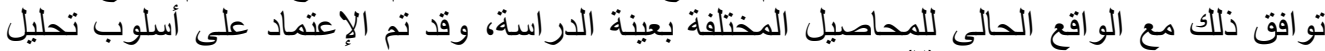

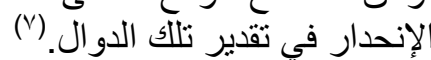
1- الإن دوال تكاليف محصول الطماطر

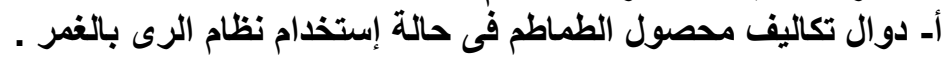

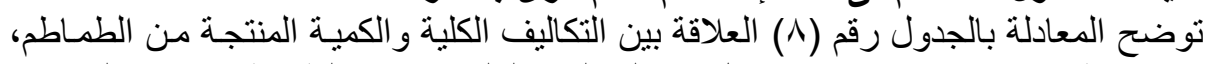

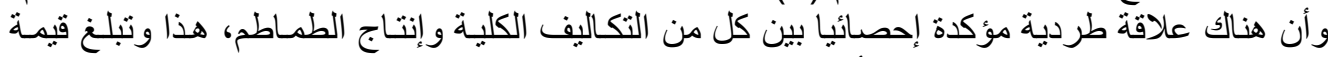

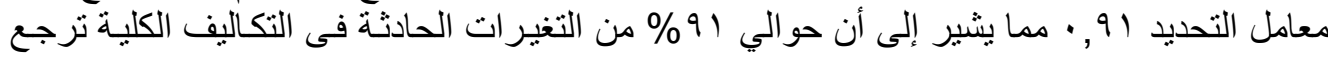

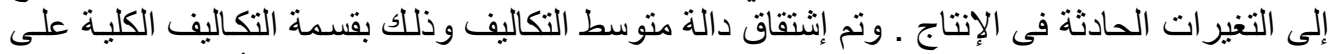

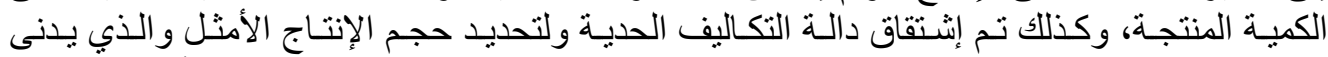

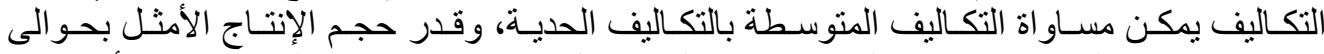

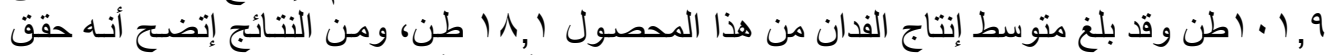

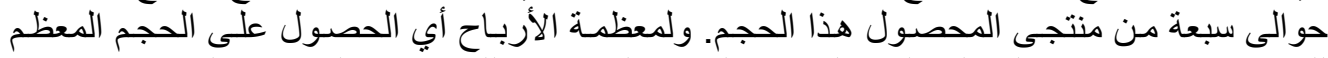

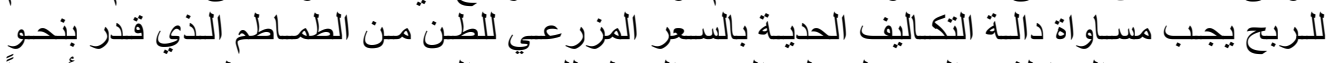

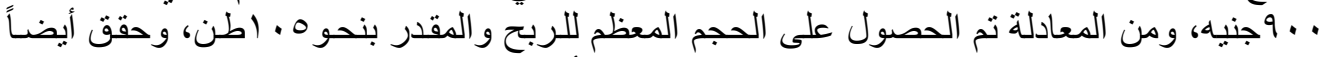

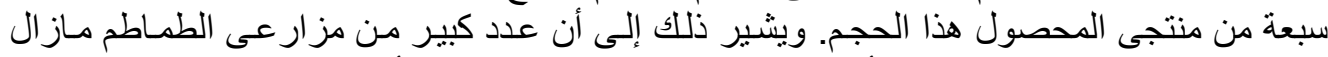

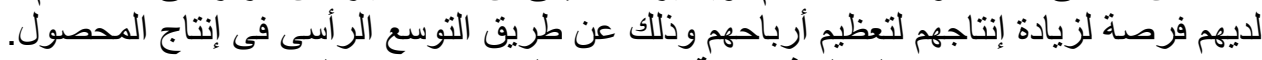

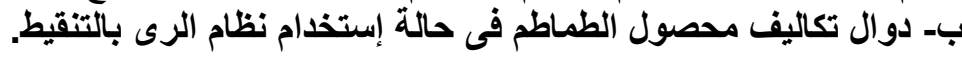

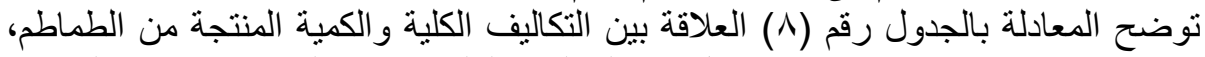

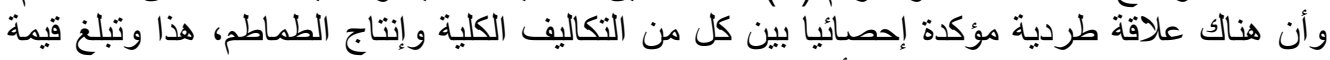

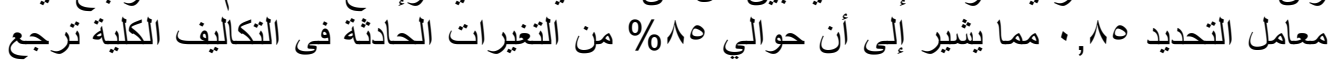

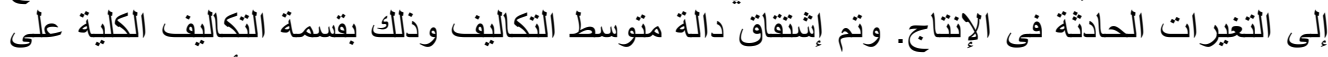

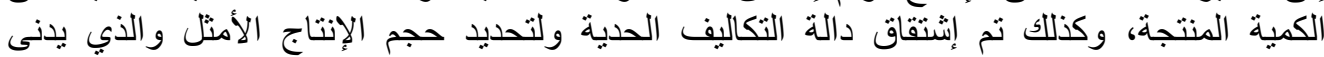

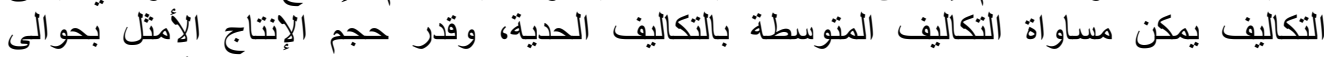

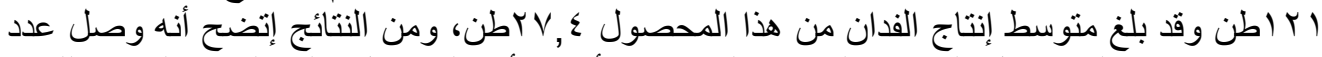


Fayoum J. Agric. Res. \& Dev., Vol. 30, No.2, July, 2016 
$\Lambda \varepsilon$

يجب مساواة دالة التكاليف الحدية بالسعر المزرعي للطن من الطماطم الذي قدر بنحو ل ... اجنيه،

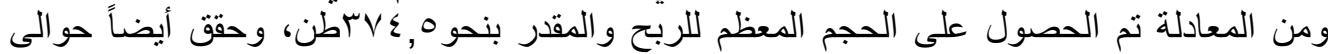

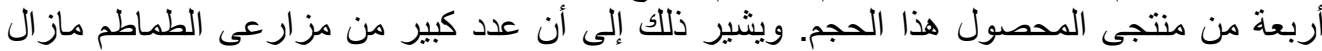

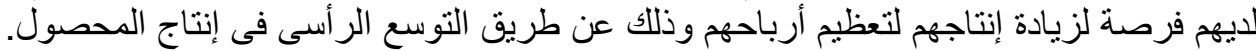

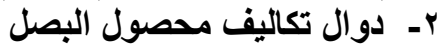

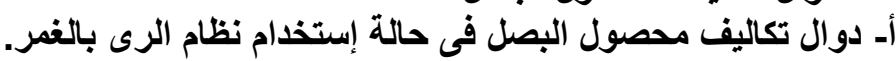

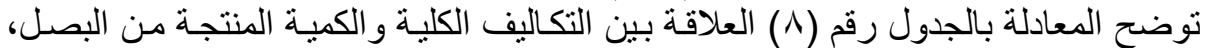

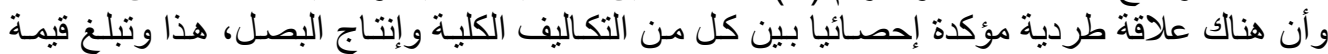

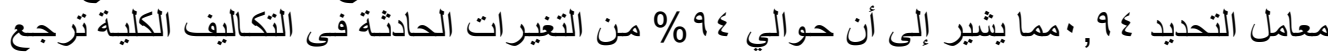

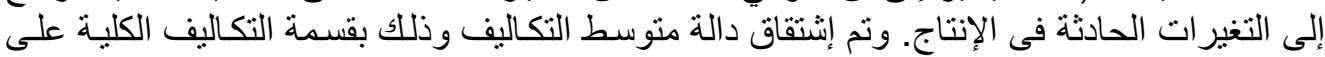

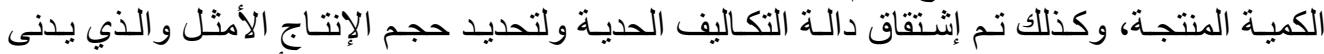

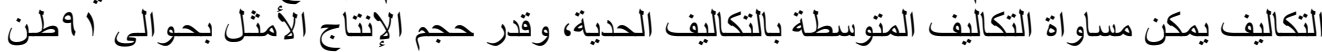

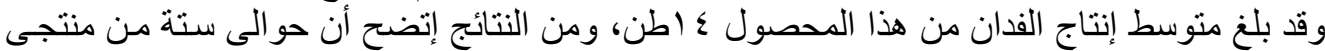

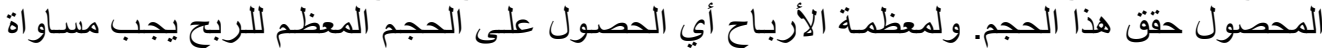

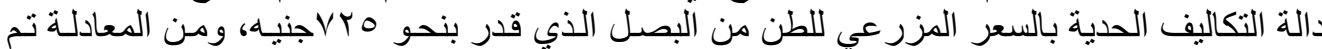

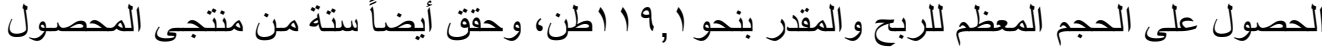

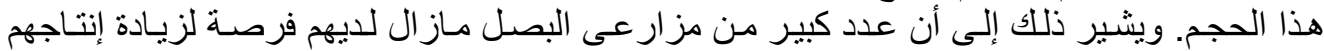

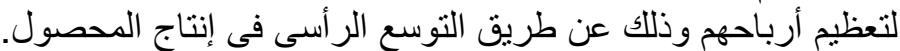

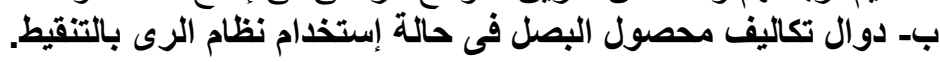

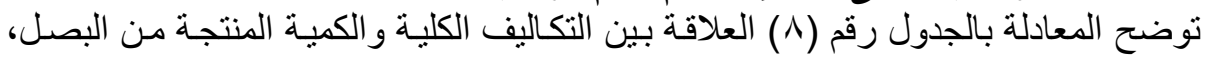

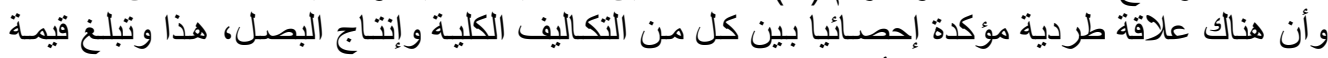

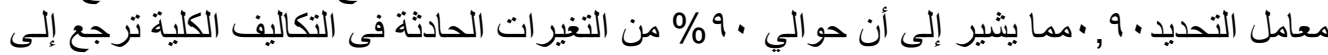

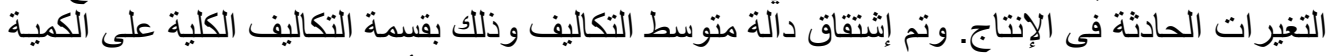

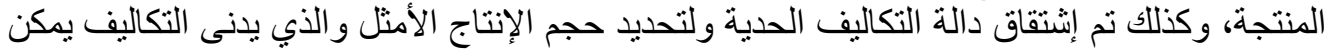
مساو اة التكاليف المنوسطة بالتكاليف الحدية، هذا وقد قدر بنحو التحو

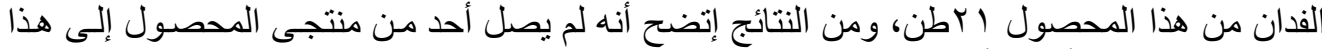

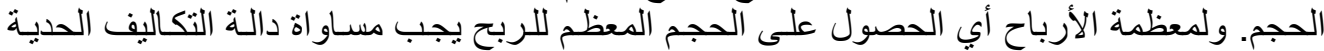

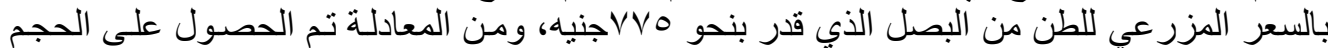

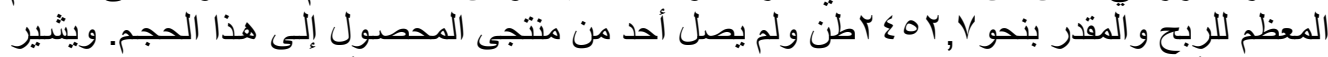

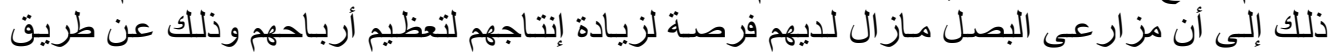

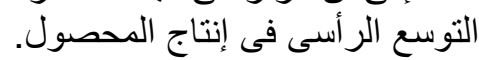

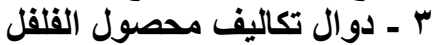

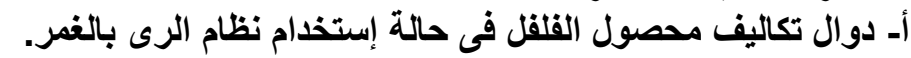

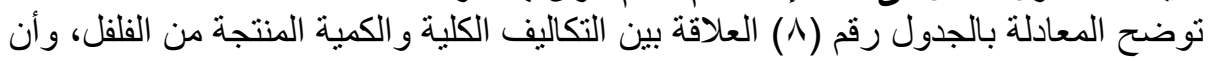

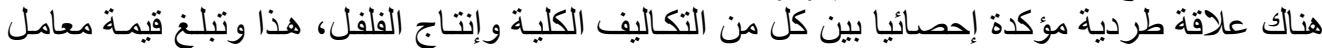

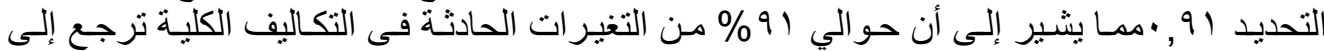

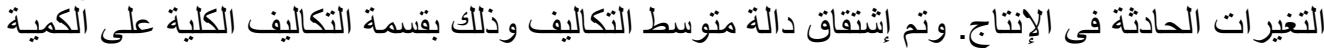

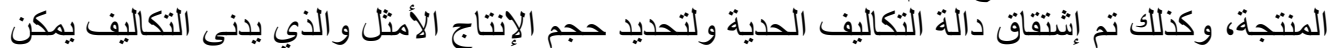

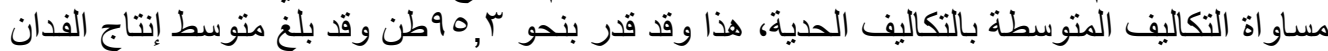

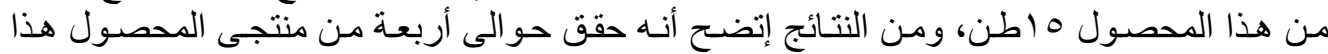

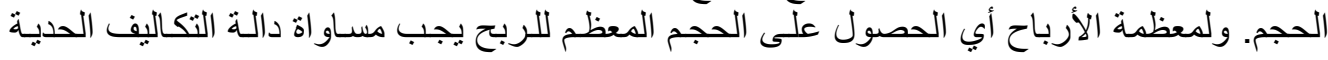

Fayoum J. Agric. Res. \& Dev., Vol. 30, No.2, July, 2016 
^॰

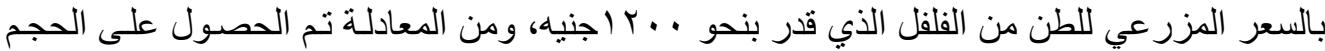

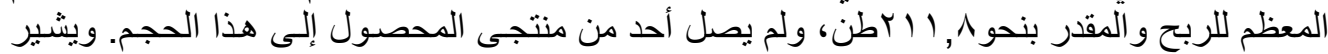

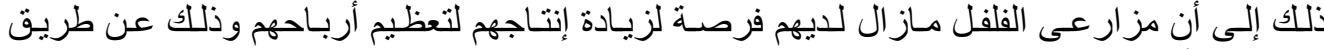

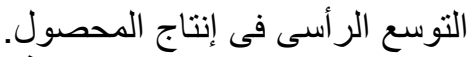

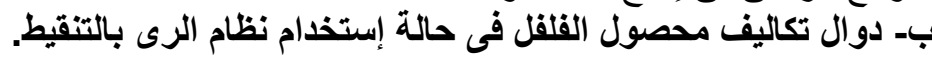

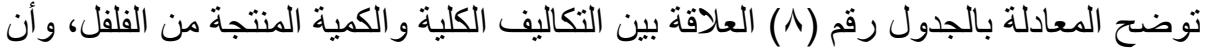

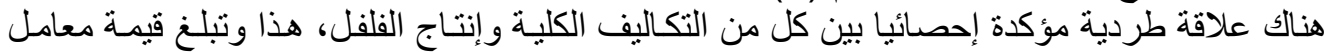

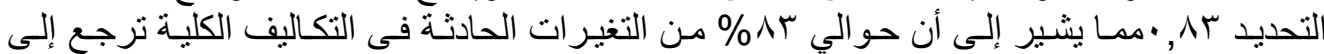

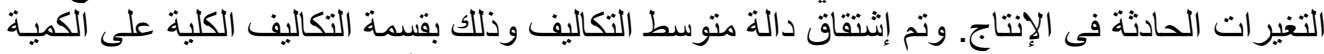

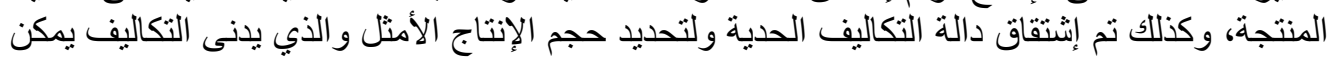

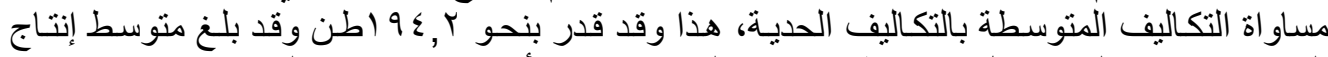

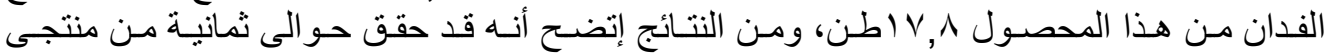

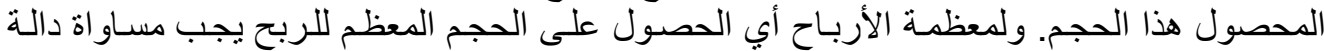

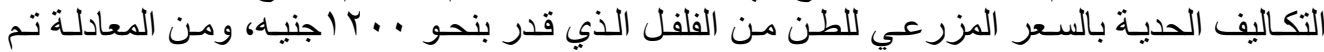

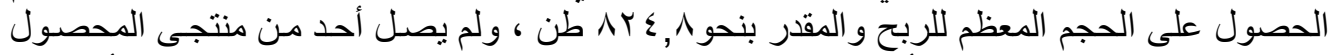

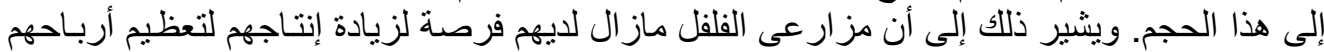

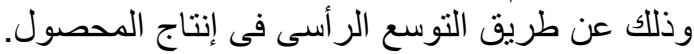

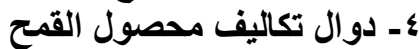
أـ دوال تكاليف محصول القمح في حالة إستخدام نظام الرى بالغمر.

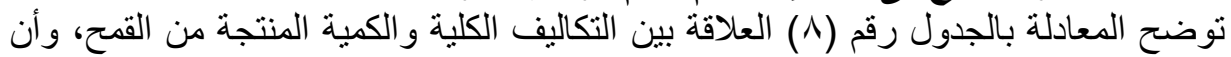

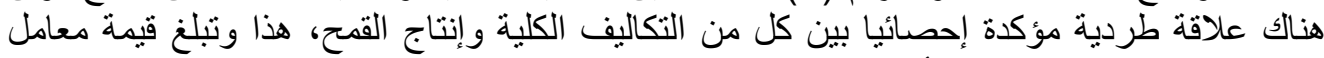

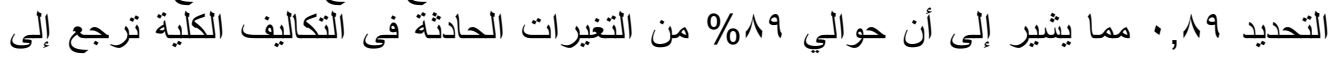

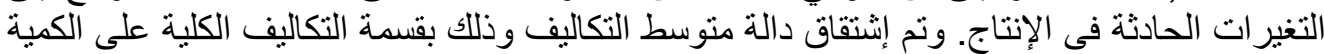

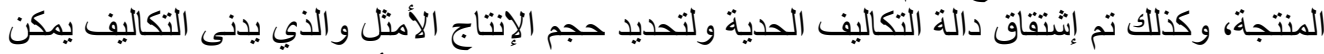

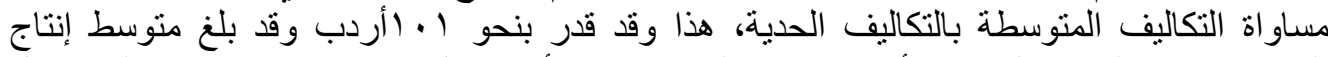

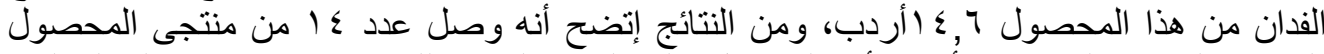

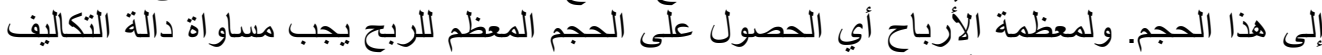

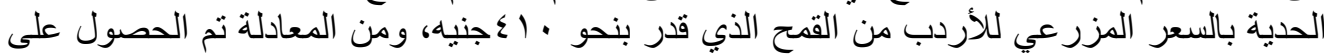

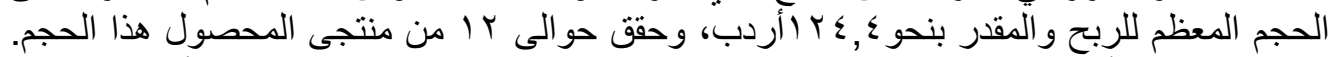

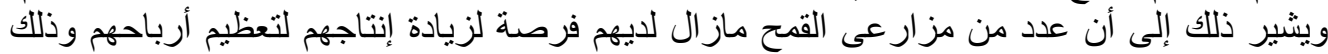

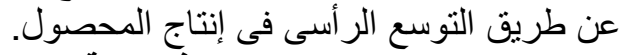

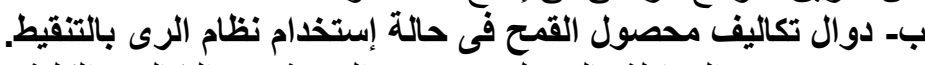

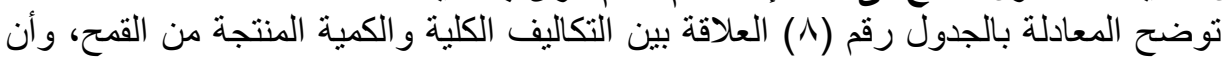

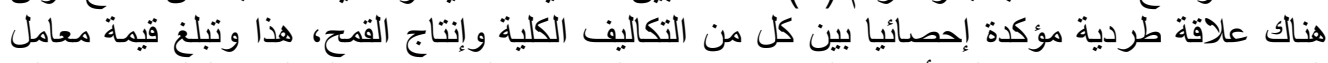

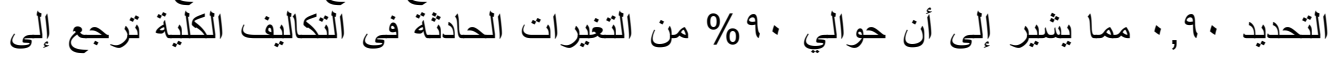

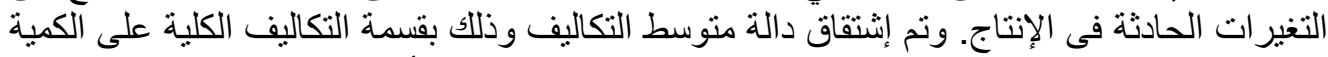

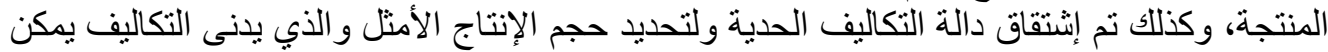

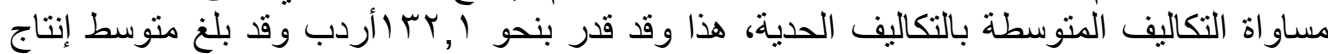

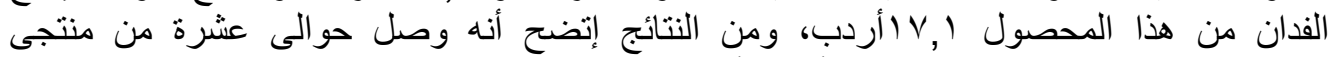

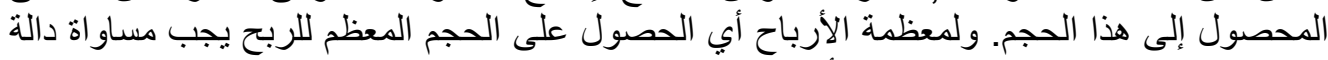

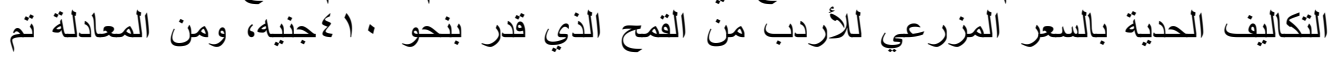

Fayoum J. Agric. Res. \& Dev., Vol. 30, No.2, July, 2016 
$\wedge 4$

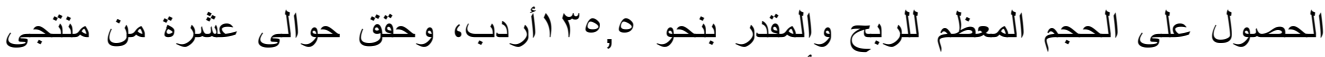

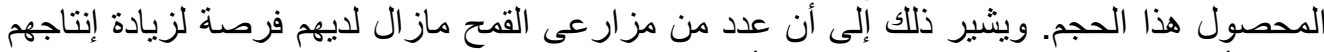

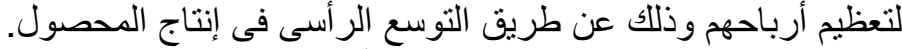

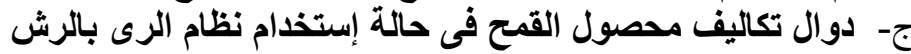

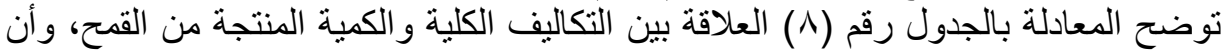

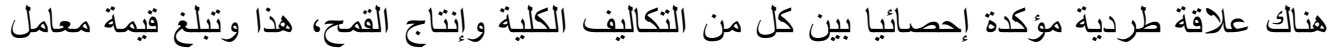

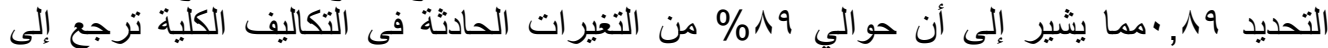

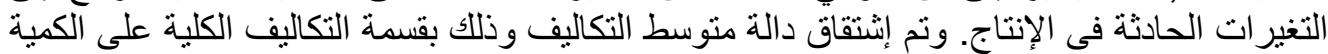

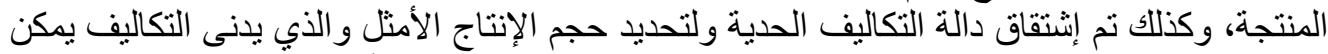

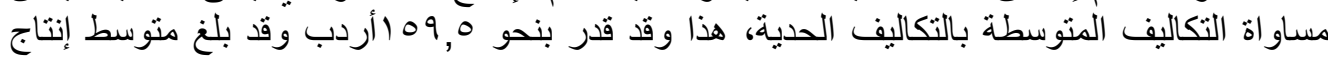

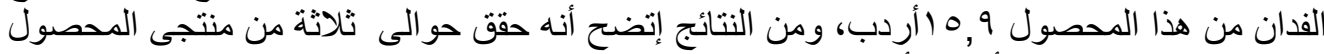

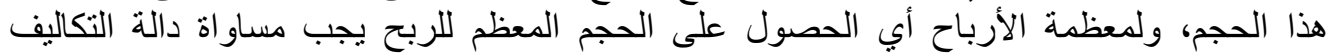

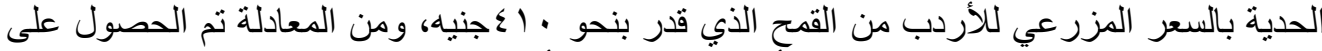

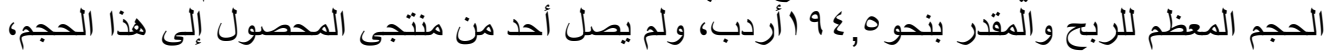

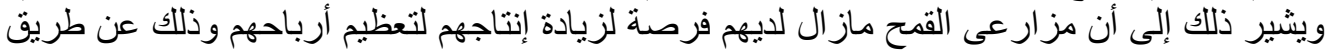

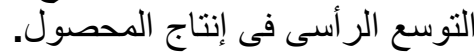
جدول رقم (^): دوال التكاليف لمحاصيل الدراسة فى الأراضى الجديدة بمحافظة بنى سويف وفقاً

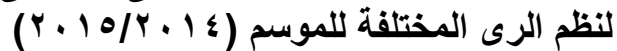

\begin{tabular}{|c|c|c|c|c|}
\hline ف & ru & ألمعادلات & نظام الرى & المحصول \\
\hline$v 1, v$ & $\cdot, 91$ & 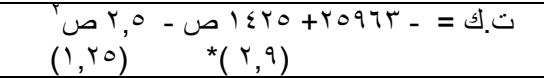 & غمر & \multirow{2}{*}{ الطماطم } \\
\hline$r r \cdot, \varepsilon$ & $\cdot, \wedge 0$ & 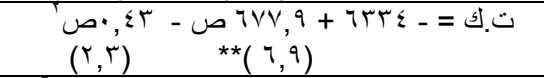 & تنقيط & \\
\hline $1 \cdot \varepsilon, r$ & $\cdot, 9 \leqslant$ & 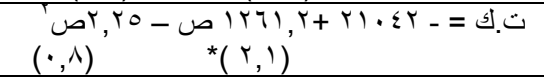 & غمر & \multirow{2}{*}{ البصل } \\
\hline$r r \cdot, l$ & $\cdot, 9$. & 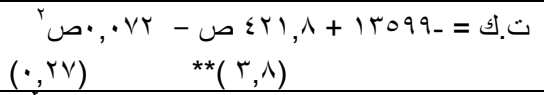 & تنقيط & \\
\hline$\varepsilon \cdot, r$ & $\cdot, 91$ & 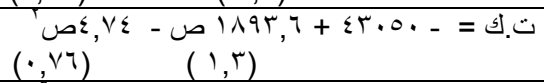 & غمر & \multirow{2}{*}{ القلقل } \\
\hline IrE & $\cdot, \wedge r$ & 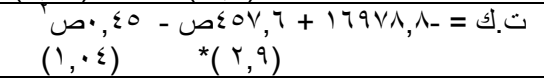 & تنقيط & \\
\hline $1 Y \cdot, T$ & $\cdot, \wedge 9$ & 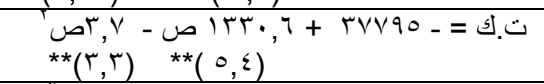 & غمر & \multirow{3}{*}{ القمح } \\
\hline$q \cdot, v$ & $\cdot, 9$. & $\begin{array}{c}(1,9), 004-0.009,9+977 V_{-}=5.5 \\
(1,9) \\
* *(0,7)\end{array}$ & تنقيط & \\
\hline$\wedge \uparrow, \varepsilon$ & $\cdot, \wedge 9$ & 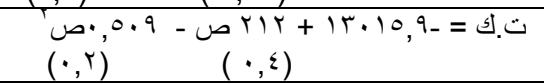 & رش & \\
\hline
\end{tabular}

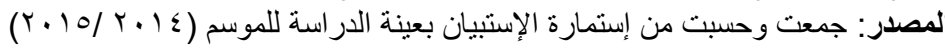

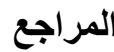

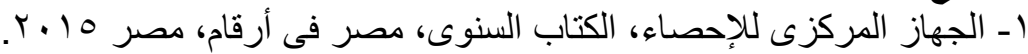

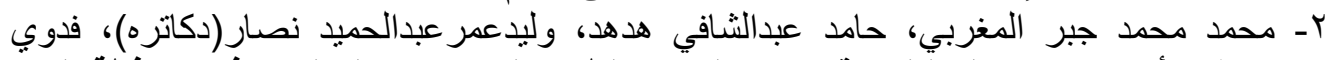
مصطفي أحمد حسين، التحليل الاقتصادي المقارن لطرق الري ملئي محصول القمح في محافظة المنيً

Fayoum J. Agric. Res. \& Dev., Vol. 30, No.2, July, 2016 


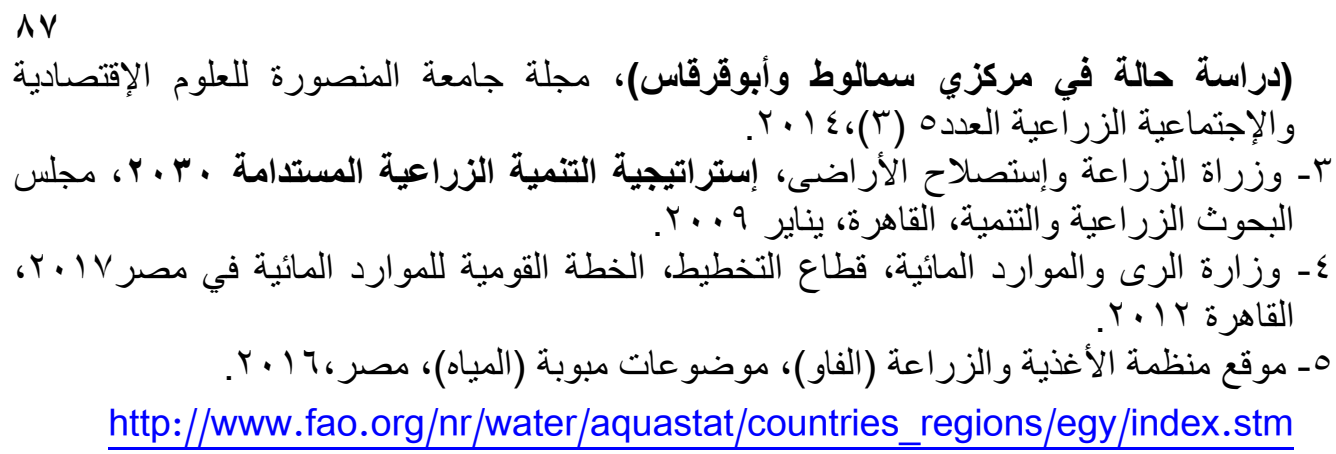

1- Walter Nicholson ,Christopher M. Snyder, Microeconomics Theory:

Basic Principles and Extensions, teen edition, united state, 2008.

2- Henderson (JamesH.), Quandt (Richard E.), Microeconomic Theory: A

Mathematical Approach, International Edition, September 1, 1980

\title{
ECONOMIC RETURNS OF IRRIGATION SYSTEMS FOR THE MOST IMPORTANT CROPS IN NEW LANDS IN BENI SUEF GOVERNORATE
}

\begin{abstract}
ABESTRACT
This study aims to determine the most appropriate irrigation systems that achieve higher economic efficiency in the production of the most important crops in Beni Suef, determines the potential for horizontal expansion in Beni Suef according to water resources available and under use of modern irrigation systems. The main findings are summarized as following: Changes in productivity, amount of irrigation water, cultivated area, and the production \& economic efficiency of the unit of irrigation water are reported as follow. As for tomatoes, productivity has increased by 9.3 tons in case of drip irrigation which represent an increase of $51.38 \%$ compared to productivity in flood irrigation. As for onion, productivity has increased by 6.9 tons in case of drip irrigation which represent an increase of $49.3 \%$ compared to productivity in flood irrigation. As for pepper, productivity has increased by 2.9 tons in case of drip irrigation which represent an increase of $19.5 \%$ compared to productivity in flood irrigation. As for wheat, productivity has increased by 2.5 and 0.95 bushels in case of drip irrigation and sprinkle irrigation respectively, which represent an increase of $16.7 \%$ and $6.5 \%$ compared to productivity in flood irrigation. The drip irrigation system in tomatoes is proved to reduce water consumption per feddan of tomato of about 454 cubic meters compared to flood irrigation. Change flood irrigation system into dripping system may save about 5.22 million cubic meters for Beni Suef and about 141.6 million cubic meters for Egypt. The preserved amount of water can be used to expand the area cultivated with tomatoes by about 2.2, 59.5 thousand feddans for Beni Suef and Egypt respectively. The drip
\end{abstract}

Fayoum J. Agric. Res. \& Dev., Vol. 30, No.2, July, 2016 
$\wedge \wedge$

irrigation system in onion is proved to reduce water consumption per feddan of tomato of about 450 cubic meters compared to flood irrigation. Change flood irrigation system into dripping system may save about 3.3 million cubic meters for Beni Suef and about 22 million cubic meters for Egypt. The preserved amount of water can be used to expand the area cultivated with onion by about 2 and 13.4 thousand feddans for Beni Suef and Egypt respectively considering that the water requirements per feddan of onion is 1650 cubic meters. The drip irrigation system in pepper is proved to reduce water consumption per feddan of tomato of about 542 cubic meters compared to flood irrigation. Change flood irrigation system into dripping system may save about 1.95 million cubic meters for Beni Suef and about 40.5 million cubic meters for Egypt. The preserved amount of water can be used to expand the area cultivated with onion by about 0.72 and 15 thousand feddans for Beni Suef and Egypt respectively. As for wheat, the drip irrigation system in wheat is proved to reduce water consumption per feddan of tomato of about 470 cubic meters compared to flood irrigation. Change flood irrigation system into dripping system may save about 4.4 million cubic meters for Beni Suef and about 292.3 million cubic meters for Egypt. The preserved amount of water can be used to expand the area cultivated with onion by about 2.5 and 166 thousand feddans for Beni Suef and Egypt respectively. The sprinkle irrigation system in wheat is proved to reduce water consumption per feddan of tomato of about 250 cubic meters compared to flood irrigation. Change flood irrigation system into dripping system may save about 4.3 million cubic meters for Beni Suef and about 155.5 million cubic meters for Egypt. The preserved amount of water can be used to expand the area cultivated with onion by about 1.2 and 78.5 thousand feddans for Beni Suef and Egypt respectively.

The study Recommendations:

Expand the use of modern irrigation systems in the new lands for various agricultural crops as it may increase the area cultivated of investigated crops. Provide irrigation kits with reasonable prices to farmers through agricultural associations to encourage farmers to switch from flood irrigation to modern irrigation, especially in the new land dedicated to graduates.

Fayoum J. Agric. Res. \& Dev., Vol. 30, No.2, July, 2016 